
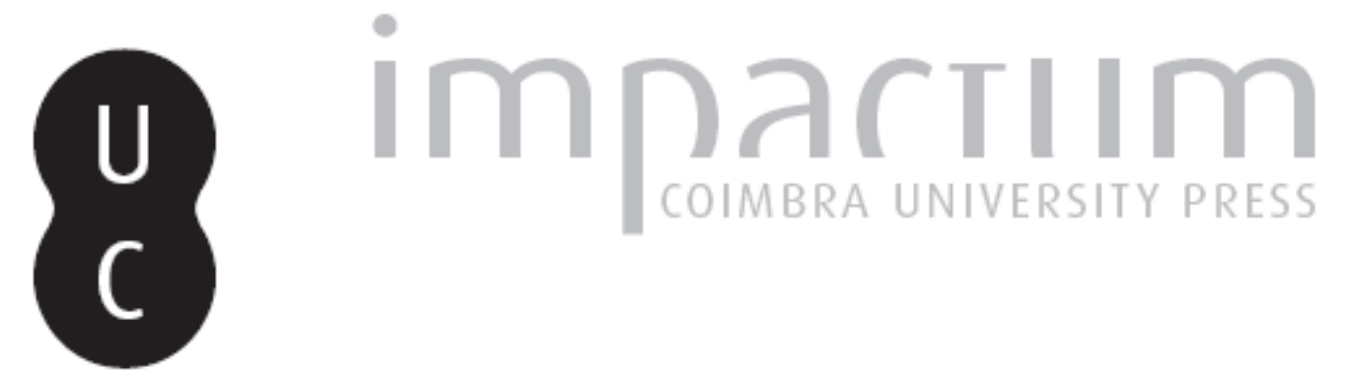

\title{
A erosão nas praias do Cabo Mondego à Figueira da Foz (Portugal centro-oeste), de 1995 a 1998
}

Autor(es): $\quad$ Cunha, P. Proença; Dinis, J.

Publicado por: Associação Portuguesa de Riscos, Prevenção e Segurança

URL persistente:

URI:http://hdl.handle.net/10316.2/40133

DOI:

DOl:https://doi.org/10.14195/1647-7723_5_3

Accessed : $\quad$ 26-Apr-2023 10:31:58

A navegação consulta e descarregamento dos títulos inseridos nas Bibliotecas Digitais UC Digitalis, UC Pombalina e UC Impactum, pressupõem a aceitação plena e sem reservas dos Termos e Condições de Uso destas Bibliotecas Digitais, disponíveis em https://digitalis.uc.pt/pt-pt/termos.

Conforme exposto nos referidos Termos e Condições de Uso, o descarregamento de títulos de acesso restrito requer uma licença válida de autorização devendo o utilizador aceder ao(s) documento(s) a partir de um endereço de IP da instituição detentora da supramencionada licença.

Ao utilizador é apenas permitido o descarregamento para uso pessoal, pelo que o emprego do(s) título(s) descarregado(s) para outro fim, designadamente comercial, carece de autorização do respetivo autor ou editor da obra.

Na medida em que todas as obras da UC Digitalis se encontram protegidas pelo Código do Direito de Autor e Direitos Conexos e demais legislação aplicável, toda a cópia, parcial ou total, deste documento, nos casos em que é legalmente admitida, deverá conter ou fazer-se acompanhar por este aviso.

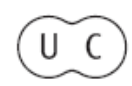




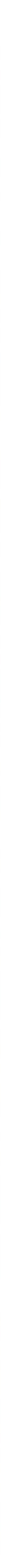




\title{
A erosão nas praias do Cabo Mondego à Figueira da Foz (Portugal centro-oeste), de 1995 a 1998*
}

\author{
P. Proença Cunha" \\ J. Dinis
}

Resumo:

Descreve-se a intensa erosão que desde finais de 1995 afectou o litoral entre o Cabo Mondego e a Figueira da Foz, focando em particular o recuo da linha de costa verificado com a progressiva perda de areia da praia, seguida do desmoronamento do enrocamento da marginal oceânica a norte de Buarcos e, posteriormente, da erosão na faixa arenosa entre Buarcos e Figueira da Foz. Além de uma periódica monitorização foi feita análise de dados da ondulação, marés, características dos sedimentos e volumes de extracção de areia na praia. Tendo em conta a influência relativa de parâmetros tais como o fornecimento sedimentar, deriva litoral e características da agitação marítima, compara-se a evolução deste sector litoral com a dos adjacentes e apresenta-se um modelo explicativo para este intenso fenómeno erosivo local. Concluiu-se que a contínua erosão destas praias verificada após o temporal de Janeiro de 1996, foi essencialmente devida uma alteração das características habituais da ondulação; os rumos médios mais rodados para W reduziram a transposição de areia para sul do Cabo Mondego, induzindoum défice sedimentar no seguinte troço costeiro. Palavras-chave:

Erosão costeira, deriva litoral, défice sedimentar, abastecimento sedimentar, ondulação, linha de costa, Portugal.

Resumé:

On présente une synthèse de la intense érosion côtière qui a affectée, dès 1995, le littoral portugais entre le Cap Mondego et le port de Figueira da Foz (embochure du Mondego), en particulier le progressive recul du rivage, les modifications dans la plage et la destruction de constructions au long du littoral. Les observations attestent une modification importante du profil de la plage de Buarcos-Figueira da Foz, à cause de l'érosion de 2,5 métres d'épaisseur maximale de sable suivit par le glissement du mur de protection et d'une partie de l'avenue côtière. Le fenomène s'interprete par une rotationver l'ouest de la direction moyenne de l'ondulation, qui a causée le déficit sedimentaire de la dérive littoral au sud du Cap Mondego. Mots clé:

Érosion côtière, dérive littoral, déficit sedimentaire, ondulation, rivage, Portugal.

\section{Abstract:}

A winter storm followed by unusual wave characteristics during 1996-1998 caused intense erosion of the Cape Mondego-Figueira da Foz beaches. This coast located southwards of an important natural headland, showed widespread beach erosion in a negative sedimentary budget (sand starvation) caused by an unusual mean direction of the waves (reduction of the NW and increase of the SW). The main effect on the coastal morphology was a large erosion of the beach sand which progressively lead to the destruction of a roadway seawall built on the beach sand. Planning and management of this coast should include higher restrictions to human activities on the coast (constructions, sand mining, etc.) and rivers, but also request monitoring studies to understand rapid sedimentary evolutions and to improve the knowledge of the sedimentary dynamics which can optimise coastal antrophic interventions in order to avoid risks, expensive repairs and negative impacts to adjacent beaches.

Key words:

Coastal erosion, littoral drift, sand starvation, sand supply, wave regime, shoreline, Portugal.

\section{Introdução}

\section{Objectivos}

Foram analisados os principais aspectos associados à intensa erosão costeira que afectou, a partir de finais de 1995, o troço litoral entre o Cabo Mondego e Figueira da Foz, focando em particular o progressivo recuo da linha de costa que culminou com enormes estragos no enrocamento da estrada marginal oceânica

\footnotetext{
* Trabalho iniciado no âmbito do projecto PEAMB/C/GEN247/93 (INICT/ DGA): "Avaliação das modificações antrópicas actuais nos sub-ambientes sedimentares do Estuário do Mondego".

*:* Grupo de Estudo dos Ambientes Sedimentares - Centro de Geociências da Univ. Coimbra;

Departamento de Ciências da Terra da F.C.T.U.C., 3049 Coimbra Codex, Portugal. pcunha@cygnus.ci.uc.pt; jodinis@cygnus.ci.uc.pt
}

para norte do Forte de Buarcos e seguido de erosão no areal de Buarcos.

As observações integram-se numa monitorização da faixa de praia, essencialmente obtidas através de um periódico registo fotográfico (no terreno e aéreo, em especial dos locais com rápida evolução topográfica) e da execução de perfis topográficos de praia. A análise de outras informações de diversa índole, em especial a ondulação, marés, características dos sedimentos e volumes da extracção de areia na praia (S. Jacinto e Figueira da Foz) (Cunha et al., 1997b), permitiram interpretar esta evolução erosiva costeira.

\section{Localização}

O troço litoral analisado situa-se na Beira Litoral (Portugal Centro-ocidental) e é adjacente ao Estuário 
do Mondego, em cuja embocadura se situa a cidade da Figueira da Foz. O Cabo Mondego corresponde ao paralelo de $40^{\circ} 10^{\prime} \mathrm{N}$ e ao meridiano de $8^{\circ} 52^{\prime} \mathrm{W}$ (Fig. 1).

Figura 1 - Litoral imediatamente a sul do Cabo Mondego e sua localização na costa ocidental portuguesa (adaptada da Carta hidrográfica da Barra e

Porto da Figueira da Foz, 1985; escala 1/10.000).

Estão assinalados os locais referidos no texto.

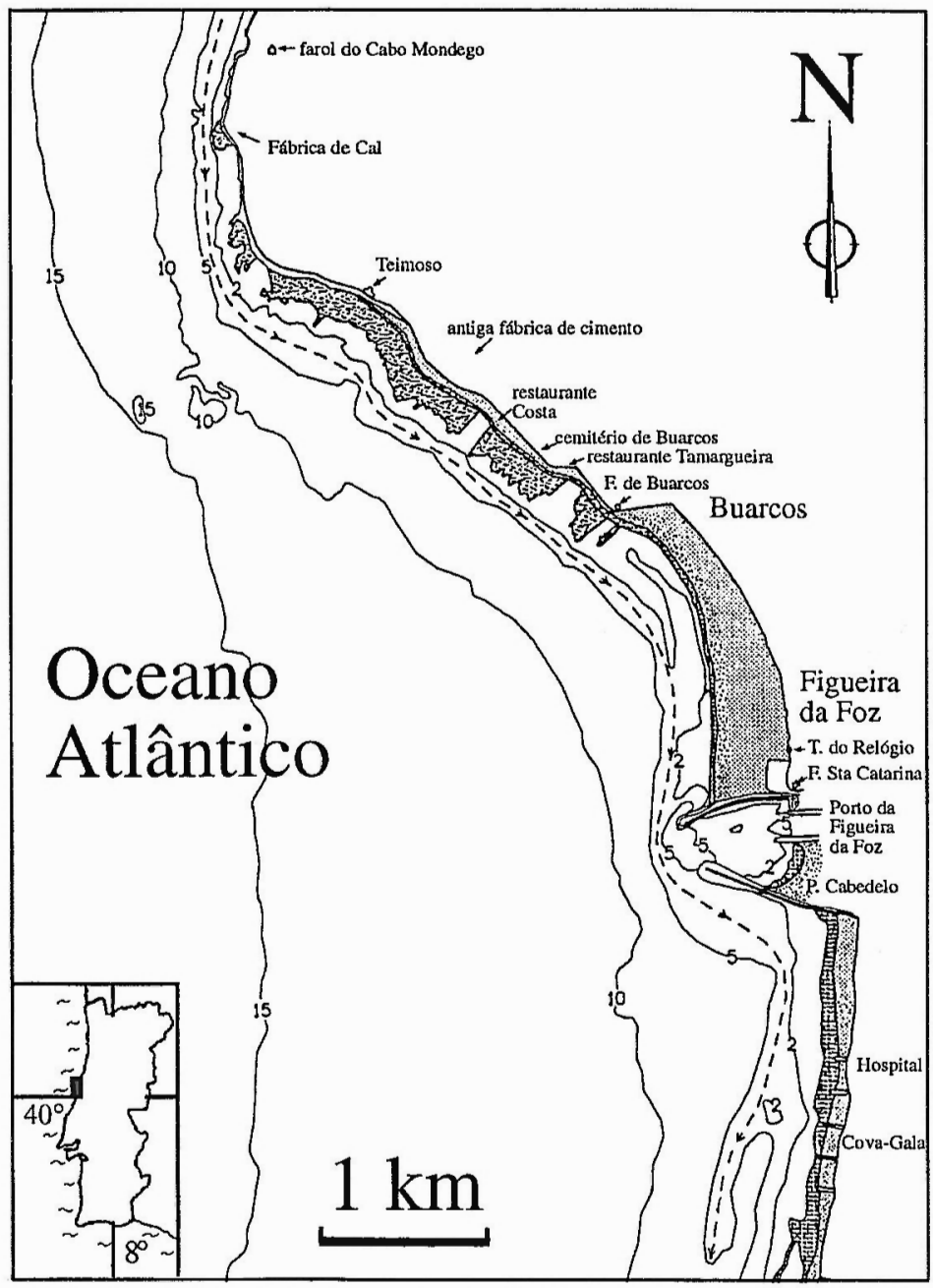

\section{Geomorfologia}

Imediatamente a norte da foz do Mondego existe uma faixa arqueada de relevos de baixa altitude (entre 100 e $258 \mathrm{~m}$ ), orientada segundo WNW-ESE, em cuja extremidade ocidental se salienta a Serra da Boa Viagem e o Cabo Mondego. No Cabo Mondego a costa está talhada em arriba, na base da qual se estende uma plataforma rochosa de abrasão marinha que se prolonga para além da linha de baixa-mar viva. Para norte inicia-se uma extensa faixa de praia arenosa que se prolonga até Espinho, numa direcção geral NNE-SSW. Imediatamente para sul do Cabo Mondego a costa inflecte para SEe, depois de Buarcos, vai rodando progressivamente para sul, até que, a cerca de $4 \mathrm{~km}$ a sul da embocadura do Mondego, retoma um traçado rectilíneo com direcção aproximada SSW (Fig. 1). A norte da Serra da Boa Viagem e a sul do Mondego existem extensos campos dunares eólicos.

\section{Batimetria dos fundos marinhos}

Para profundidades superiores a $25 \mathrm{~m}$ os fundos marinhos não apresentam irregularidade na passagem do Cabo Mondego, mantendo o traçado geral da costa (Fig. 1).

As batimétricas acima de $-5 \mathrm{~m} \mathrm{ZH}$ (nível de zero hidrográfico) são fortemente influenciadas pela presença dos molhes exteriores do porto, de modo que, por exemplo, a batimétrica de $0 \mathrm{~m} \mathrm{ZH}$ se encontra desfasada para leste cerca de $600 \mathrm{~m}$ para sul da embocadura. Mais ao largo, paralelamente à linha de costa, os levantamentos topo-hidrográficos mostram que a barra submersa exterior apresenta geralmente cerca de $300 \mathrm{~m}$ de largura e $4 \mathrm{~m}$ de altura; na embocadura, esta barra arenosa contorna o molhe norte, verificandose um significativo adelgaçamento junto à cabeça do molhe sul. É provável que uma parte significativa do transporte litoral se faça ao longo desta barra, numa faixa situada aproximadamente aos $-3 \mathrm{~m}$ de profundidade. 
Oanteportoé limitado por dois molhes convergentes cujas cabeças e enraizamentos se afastam de, respectivamente, 325 e $800 \mathrm{~m}$. O molhe norte, com $900 \mathrm{~m}$ de extensão, enraíza próximo do Forte de Santa Catarina; o molhe sul, com $950 \mathrm{~m}$ de extensão, enraíza na praia do Cabedelo. O canal central de navegação apresenta cotas médias de $-4 \mathrm{~m} \mathrm{ZH}$ e áreas adjacentes com profundidade substancialmente menor; este sector é objecto de periódicas dragagens para a manutenção de cotas necessárias à navegação, devido a assoreamento principalmente marinho. A embocadura define-se entre os molhes interiores, sendo de $170 \mathrm{~m}$ a largura do canal de acesso que atinge cotas até $-7 \mathrm{~m} \mathrm{ZH}$. Entre os molhes exteriores e os interiores criaram-se duas praias (cabedelos), sendo a de sul mais vasta e em parte herdada da situação anterior à construção dos molhes.

\section{Regime de ventos}

Com base nos dados recolhidos na estação climatológica na Barra do porto da Figueira da Foz, de 1953 a 1970, as condições climatéricas da área caracterizaram-se por ventos fortes, mais frequentes com rumos dos quadrantes $\mathrm{N}$ e $\mathrm{NW}$, e a frequência das calmas é baixa; o regime de ventos é muito irregular entre anos, mas uma das características mais constantes é o predomínio dos ventos de norte (nortada) nos meses de verão (percentagem média de $33 \%$ ) (Consulmar, 1973; Impacte, 1993). Note-se que os ventos de maior velocidade média pertencem ao quadrante $S W$, que tem também a maior frequência de velocidades superiores a $20 \mathrm{~km} / \mathrm{h}$. A acção regional destes ventos fortes do quadrante SW pode gerar ondas capazes de se propagarem com intensidade no interior do estuário terminal (SANTOS et al., 1991; Almeida, 1991; Almeida \& Santos, 1991), podendo explicar situações (conhecidas como "mareta") muito prejudiciais para a actividade portuária.

\section{Caracterização anual do clima de agitação marítima}

A dinâmica marinha actual na costa portuguesa é essencialmente condicionada pela circulação atmosférica a oeste, no Atlântico. Durante a maior parte do ano, com o anticiclone próximo dos Açores, existe ondulação de NW. A menos frequente ondulação de W e SW está associada a focos depressionários e à passagem das respectivas superfícies frontais.

A agitação na orla marítima adjacente à Figueira da Foz foi registada, pela Junta Autónoma do Porto da Figueira da Foz, entre Janeiro de 1954 e Dezembro de 1960. As observações a partir da "Torre do Relógio" foram efectuadas três vezes ao dia, só na parte diurna, efectuando-se registos simultâneos dos valores da altura, rumo e período da agitação.

Neste período de sete anos a altura significativa máxima não ultrapassou os $7,5 \mathrm{~m}$; contudo, não ficaram registados períodos de forte agitação devido a ruptura do cabo de amarração da bóia durante tempestades e à má visibilidade por nevoeiro, chuva, etc.. Carvalho \& Barceló (1966) procederam à transposição para o largo dos valores observados em pequenas profundidades, utilizando planos de refracção. De acordo com esse estudo, a costa está sujeita a uma agitação marítima em que a ondulação tem altura mais frequente (42\%) da ordem de 1-2 m. Os resultados estão sintetizados na Tab. 1 .

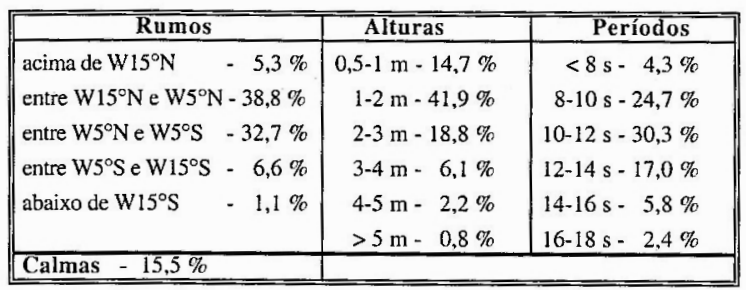

Tabela 1 - Características da ondulação ao largo do Porto da Figueira da Foz (Carvalho \& Barcelo, 1966),

De acordo com a análise de registos ao longo da costa portuguesa, o rumo de WNW é predominante durante todas as estações do ano, com $44,7 \%$ das ocorrências no verão, $28,9 \%$ nos períodos de transição e 22,6 \% no inverno; a agitação de oeste atinge o máximo claramente no inverno, com $21 \%$ das observações (ConsulmaR, 1973).

Mais recentemente, também com base nos registos efectuados na "Torre do Relógio" (1954-60), SANTos et al.(1991) efectuaram a caracterização anual, quadrimensal e mensal do clima de agitação marítima na zona de entrada do porto da Figueira da Foz, considerando o trinómio indissociável altura-rumo-período. Destacam-se os seguintes resultados da caracterização anual:

- A média dos valores não nulos das alturas significativas de agitação é de $1,8 \mathrm{~m}$;

- Com maior frequência encontram-se as classes $1,0-1,5 \mathrm{~m}$ (24\%), 1,5-2 m (19\%), 0,5-1 m (15\%) e 2,0-2,5 m (10\%);

- A classe de calmas representa $17 \%$ e a classe $0-0,5 \mathrm{~m}$ cerca de $1 \%$;

- As situações de temporal podem classificar-se nas classes $5-6,5 \mathrm{~m}(1 \%$, com rumos predominantes entre os $\mathrm{N} 262-282^{\circ}$ e períodos de $13-18 \mathrm{~s}$ ) e na de

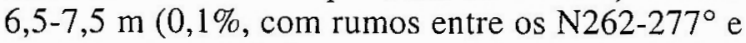
períodos de 13-19 s).

- A agitação praticamente só apresenta rumos de N242-297\%, existindo efeitos de refracção e difracção provocados pelo Cabo Mondego;

- As classes mais frequentes são as de N272-277 (29\%), N267-272 ${ }^{\circ}(20 \%)$ e N277-282 $(16 \%)$; o rumo médio da ondulação é de $\mathrm{N} 273^{\circ}$;

- A ondulação mais alta está rodada para SW, pois as alturas significativas $>5 \mathrm{~m}$ correspondem a rumos de $\mathrm{N} 247-282^{\circ}$;

- Os períodos mais frequentes são entre 7-13 s. 


\section{Caracterização quadrimensal do clima de agitação maritima}

Para a definição do clima de agitação marítima, com base no regime junto à costa da Figueira da Foz, SANTOS et al. (1991) consideraram a seguinte subdivisão do ano:

- Verão (Junho, Julho, Agosto e Setembro) elevada percentagem de baixas alturas (média de 1,3 $\mathrm{m})$ e rumos a norte de $\mathrm{W}(68 \%$ com $0,5-2,5 \mathrm{~m}, \mathrm{~N} 262$ $292^{\circ}$ e $7-11 \mathrm{~s}$ ); relativamente à situação de Inverno, a orientação global está rodada para norte 5 graus;

- Inverno (Dezembro, Janeiro, Fevereiro e Março) - maiores alturas de onda (média de 2,2 $\mathrm{m}$ ), rumos muito variáveis concentrados em W ( $63 \%$ com $0,5-2,5$ $\mathrm{m}, \mathrm{N} 257-282^{\circ}$ e $8-13 \mathrm{~s}$ ) e temporais frequentes $(2,6 \%)$;

- Transição (Abril, Maio, Outubro e Novembro).

\section{Temporais}

A costa ocidental portuguesa está frequentemente sujeita à actuação de temporais (ANDRADE $e t$ al., 1996), que são os principais agentes de erosão costeira, gerando agitação marítima que atinge o litoral através da rebentação de ondas enérgicas de longo período. Segundo os valores calculados por CARVALHO (1992) para a Figueira da Foz, temporais com ondas de altura máxima significativa de 9,5-10,0 m têm um período de retorno de 5 anos; com um período de retorno de 50 anos estima-se uma altura máxima significativa de 11,5-13,6 m (Tab. 2). As situações de tempestade que resultam de baixas pressões ligadas à passagem de perturbações atmosféricas são acompanhadas de significativa sobrelevação meteorológica do nível do mar, permitindo que a ondulação possa atingir áreas mais interiores, sendo mais relevante quando coincidente com a praia-mar de marés vivas; lembre-se o importante galgamento na Cova e a erosão costeira gerada pelo temporal de 1978 , bem como os efeitos do temporal de Janeiro de 1996 (F. Rebelo, 1978; Cunha, 1997).

Relativamente à agitação anual à entrada do Porto da Figueira da Foz (SAntos et al. (1991) importa salientar que:

- Nos meses de Dezembro, Fevereiro e Março os valores máximos da altura significativa são de 7-7,5 $\mathrm{m}$ e as percentagens de ocorrência de temporais são de $4,5 \%, 2,4 \%$ e $2,9 \%$, respectivamente;
- Os meses de Abril, Setembro, Novembro e Janeiro apresentam valores máximos da altura significativa de 6-6,5 $\mathrm{m}$ e as percentagens de ocorrência de temporais são de $1,2 \%, 1,2 \%, 2,1 \%$ e $1,1 \%$, respectivamente;

- Nos meses de Março e Abril orumo dos temporais roda para sul, enquanto que nos meses de Setembro e Novembro se centram em W.

\section{Marés}

O sector costeiro arenoso analisado possui um regime mesomareal, de tipo semi-diurno e com uma desigualdade ligeira entre as duas marés diárias. Com base na tabela de marés previstas para o Porto da Figueira da Foz durante o ano de 1996, as marés apresentaram uma amplitude média de $2,2 \mathrm{~m}$ (desvio padrão de 0,62 ) e uma moda de $2,4 \mathrm{~m}$; verifica-se que a amplitude mínima foi de $0,9 \mathrm{~m}$ (maré morta) e a máxima de 3,6 $\mathrm{m}$ (maré viva equinocial). $O$ nível médio de maré corresponde aos $+2 \mathrm{~m} \mathrm{ZH}$.

\section{Evolução recente da faixa de praia entre o Cabo Mondego e a embocadura}

Anteriormente à construção dos molhes exteriores portuários, a faixa de praia entre o Cabo Mondego e a Figueira da Foz apresentava uma largura pequena e regular, com a linha de água alinhada com o sector a sul da embocadura do Mondego. Entre 1800 e 1860 a praia da Figueira da Foz engordou cerca de $100 \mathrm{~m}$ em extensão transversal ao longo do seu comprimento (1,5m/ano). Segundo BetTencourt \& ÂNGelo (1992), no período de 1871-1947 ter-se-á verificado um recuo generalizado da linha de costa envolvente da foz do Mondego, com uma taxa média de $-0,7 \mathrm{~m} / \mathrm{ano}$ e valor máximo de $-2,3 \mathrm{~m} / \mathrm{ano}$; os mesmos autores apresentaram para o período de 1947-56 taxas máximas de $6,3 \mathrm{~m} /$ ano (avanço) para a zona a norte da embocadura e de $-3,4 \mathrm{~m} /$ ano (recuo) para a zona a sul, provavelmente reflexo das primeiras intervenções na barra do porto. Este emagrecimento progressivo até à década de 60 da praia de Buarcos-Figueira da Foz teve significativas consequências turísticas negativas, tendo ocorrido alguns problemas de erosão costeira. Note-se que já no Relatório intitulado "Ensaios laboratoriais do Porto da Figueira da Foz - estudo dos movimentos aluvionares na costa com o emprego de areias

\begin{tabular}{|c|c|c|c|c|}
\hline & \\
\hline & $\begin{array}{c}\text { Período de } \\
\text { retorno (anos) }\end{array}$ & $\begin{array}{c}\text { Cabo da Roca } \\
\text { (PIRES \& PESSANHA, 1986a,b) }\end{array}$ & $\begin{array}{c}\text { Figueira da Foz } \\
\text { (CARVALHO, 1992) }\end{array}$ & $\begin{array}{c}\text { Costa ocidental } \\
\text { (PITA \& SANTOS, 1989) } \\
\text { (FERREIRA, 1993) } \\
\end{array}$ \\
\hline & 1 & & & 6,6 \\
\hline \multirow{5}{*}{$\begin{array}{c}\text { Tabela } 2 \text { - Alturas significativas (m) da } \\
\text { ondulação associadas a períodos de retorno de } \\
\text { temporais, no sector ocidental da costa } \\
\text { continental portuguesa } \\
\text { (FERREIRA \& DIAS, 1997). }\end{array}$} & 5 & 9.5 & $9,5-10,0$ & 9,2 \\
\hline & 10 & 10,4 & & 10,3 \\
\hline & 25 & 11,4 & & 11,8 \\
\hline & 50 & 12,4 & $11,5-13,6$ & 12,9 \\
\hline & 100 & 13,1 & $12,4-15,5$ & 14,0 \\
\hline
\end{tabular}


radioactivas" (L.N.E.C., 1961) se referia que era vulgar, sempre que se prolongavam condições de agitação marítima com um rumo inferior a $\mathrm{N} 283^{\circ}$, verificar-se uma erosão total da areia da praia Cabo Mondego-Buarcos, a ponto de pôr em risco certos troços da estrada marginal.

Com base na evolução das linhas mensais de preia-mar projectadas por Vicente \& Pereira (1986), calculámos uma taxa de variação da linha de costa no troço Buarcos-Figueira da Foz, em cerca de - $8,5 \mathrm{~m} / \mathrm{ano}$ para o perfil da torre do relógio (recuo de $34 \mathrm{~m}$ ) de 1957 a 1962 , seguida de um rápido avanço $(45 \mathrm{~m} / \mathrm{ano})$ até 1969 , lento crescimento até 1982 (avanço de 106 m em 13 anos: $8,2 \mathrm{~m} / \mathrm{ano}$ ) e estabilização a partir do início de 1983.

O avanço da linha de costa iniciado em 1962 deveu-se às obras na barra que culminaram com a construção dos molhes exteriores do porto, que interromperam a deriva litoral predominante, criando uma grande acumulação arenosa a norte até que, em 1982, se atingiu a saturação da capacidade de retenção de areia pelo molhe norte; pelo contrário, a partir da construção desses molhes a costa imediatamente a sul tem sofrido um importante e contínuo recuo erosivo (Castanho et al., 1981; Duarte \& ReIS, 1992; Cunha et al., 1997a, 1997b, 1997d; Dinis \& CunHa, 1998). Segundo Cunha et al. (1995a, 1997a,b) para o sector a norte dos molhes, entre 1958 e 1977 , estimou-se que linha de praia avançou a $7 \mathrm{~m} / \mathrm{ano}$ junto a Buarcos mas mais rapidamente para sul, com o valor máximo de $478 \mathrm{~m}$ junto ao molhe exterior norte $(25 \mathrm{~m} / \mathrm{ano})$. A variação anual detalhada para este sector encontra-se expressa em VICENTE (1990), sendo evidente que a variação só atingiu valores significativos a partir do início da construção dos molhes, concluídos em 1965.

Com base em análise de fotografia aérea vertical, constata-se que no período 1977-1982 o avanço da praia foi lento, com valor médio de $4 \mathrm{~m} / \mathrm{ano}$, ainda com a taxa máxima de $17 \mathrm{~m} / \mathrm{ano}$ junto ao molhe norte. De 1982 a 1990 documenta-se uma estabilização generalizada da faixa de praia, excepto junto do molhe norte onde ocorreu um recuo de $44 \mathrm{~m}$, correspondente a $-5,5 \mathrm{~m} / \mathrm{ano}$. A inversão da tendência de enchimento, que atingiu um máximo em 1980, deveu-se também à extracção de areia da praia neste local (em média, cerca de $400 \times 10^{3} \mathrm{~m}^{3} /$ ano de 1989 a 1995) iniciada em 1977, responsável por uma alteração do perfil topográfico da praia.

Durante temporais com enérgica ondulação do quadrante SW, ou quando a extracção excedia o afluxo sedimentar, a depressão topográfica na área de extracção de areias propagava-se para norte sob a forma de uma berma erosiva. Relacionada com este último quadro estará a destruição em Janeiro de 1993 de um restaurante (apoio de praia) próximo, que tinha sido instalado em finais da década de 80 a cerca de $150 \mathrm{~m}$ da linha de preia-mar (Norvo, 1994); note-se que em Abril de 1993 a extracção atingiu o valor mensal de $40 \times 10^{3} \mathrm{~m}^{3}$.

Apesar da acumulação de areia verificada até 1980 na praia desde a Figueira da Foz até ao Teimoso (Fig. 1), a marginal era esporadicamente atingida por temporais, tendo-se efectuado em 1989 a reconstrução do enrocamento de protecção à marginal e construído escadarias de acesso à praia (Dias et al., 1994). Na década de 90 , os principais problemas localizaram-se junto a Buarcos, onde a marginal é, frequentemente, galgada pelo mar, sobretudo devido a forte ondulação de SW.

Devido ao "efeito de esporão" do Cabo Mondego, a costa a norte (a barlamar da deriva predominante) tem-se apresentado com tendência estável nas últimas décadas. As Praias de Murtinheira e de Quiaios, situadas imediatamente a norte (Fig.1), apresentam-se largas e sem problemas de erosão, excepto durante raros períodos com ondulação de $\mathrm{SW}$.

A partir da construção dos molhes exteriores portuários e das obras de regularização da bacia hidrográfica do Mondego, a costa imediatamente a sul da foz deste rio tem sofrido um contínuo e forte recuo erosivo (DuARTE \& Reis, 1992; CunHa et al., 1997a, 1997b, 1997d; Dinis \& CunHA, 1998); para além da extracção de areia na praia e barra, também a periódica execução de grandes dragagens portuárias (CunHa et al., 1995b, 1998) e as extracções de elevados montantes de areia em circulação no troço fluvial e estuarino actual contribuem para o défice sedimentar no troço litoral a sul da embocadura (Cunha, 1998a, 1998b).

\section{Transporte sólido litoral}

Oequilíbrio dinâmico de uma costa arenosa extensa e sujeita a um severo regime de agitação marítima é precário. A área adjacente à embocadura caracterizase por uma faixa de praia constituída essencialmente por areia média a grosseira, sendo abastecida por uma deriva litoral, cujo saldo sedimentar é dirigido para sul, reflexo da ondulação média de WNW. No troço entre o Cabo Mondego a Figueira da Foz, geralmente de Junho a Setembro, o transporte litoral é menos intenso mas faz-se persistentemente para sul, enquanto que nos outros meses ocorrem transportes muito importantes em ambos os sentidos. Os movimentos de areia perpendicularmente à costa, associados à variação sazonal das características da agitação, são significativos mas não se encontram quantificados.

A primeira avaliação da deriva litoral de areias que ultrapassa para sul o Cabo Mondego foi efectuada através da marcação de areias da praja, com prata radioactiva, que foram largadas (4t) na praia de Quiaios durante a baixa-mar de maré viva do dia 1 de 
Julho de 1957; seguiu-se uma recolha de cerca de 1000 amostras durante os meses de Julho, Agosto e Setembro. O posto de registo da agitação marítima, localizado junto do Cabo Mondego, registou que a ondulação nesses três meses apresentou rumos predominantes de WNW, com 1-2 m de altura média. Com base nos resultados deste estudo (L.N.E.C., 1961), em parte publicados (Gibert, 1958; GiberT et al., 1960; ABECASIs et al., 1962), salientam-se os seguintes aspectos:

- Na baixa-mar seguinte à deposição dos traçadores, o centro da respectiva massa já se encontrava a $500 \mathrm{~m}$, para sul; três dias depois deslocara-se três quilómetros, tendo já dobrado o cabo, e doze dias depois as areias radioactivas já se encontravam a sul da embocadura;

- Verificou-se movimento de areias, de norte para sul, sobre o estrão do Cabo Mondego para ondulação com um azimute superior, junto à costa, a $\mathrm{N} 283^{\circ}$ $\left(\mathrm{W} 13^{\circ} \mathrm{N}\right)$;

- Sempre que o rumo da ondulação é inferior ao azimute acima referido a areia litoral deixa de transpor o Cabo Mondego; este facto explica o emagrecimento da faixa de praia, que se estende do Cabo Mondego a Buarcos, sempre que essas situações do estado do mar se prolongam, podendo pôr em risco certos troços da avenida marginal.

- Na faixa de praia do Cabo Mondego a Buarcos o sentido de deslocação das areias faz-se sempre para a embocadura do Mondego, quaisquer que sejam os rumos da ondulação. A velocidade máxima da deriva litoral de areias foi registada neste troço da costa.

- Para além do transporte de areias no estrão do Cabo Mondego, na baía de Buarcos a deslocação das areias também se verifica numa faixa situada para fora da rebentação até profundidades iguais ou superiores a $6 \mathrm{~m}$;

- Transpondo o caudal sólido verificado nos três meses estivais de 1957 para o período de um ano calculou-se um volume de areia, que ultrapassou para sul o Cabo Mondego, em cerca de $400-550 \times 10^{3} \mathrm{~m}^{3 /}$ /ano. Note-se que no mês de Julho de 1957 ocorreram 7 dias em que a ondulação teve rumo inferior a $\mathrm{N} 283^{\circ}$.

Com base no trabalho acima referido, foram efectuadas as seguintes previsões para o que passaria a ocorrer após a conclusão dos actuais molhes exteriores:

- Nãoé possível resolver apenas com obras exteriores o problema do assoreamento com areias marinhas do sector distal da área estuarina e do aumento do banco exterior da barra;

- O banco arenoso exterior (barra submersa exterior) tende a deslocar-se durante o Verão para a barra e anteporto, devido à largura entre as cabeças dos molhes ser bastante grande;
- Em consequência, advém a necessidade de usar meios artificiais para a eliminação do caudal sólido que penetrará entre molhes, pois independentemente da solução adoptada, se não se removessem as areias, nada apontava para que as profundidades do banco exterior da barra se modificariam, mesmo a longo prazo.

Posteriormente fez-se uma avaliação do transporte sólido litoral (L.N.E.C., 1970), combase na comparação de levantamentos topo-hidrográficos realizados entre 1961 e 1966 (os molhes exteriores do porto ficaram concluídos em 1965). Essa análise estimou um caudal médio anual de $900 \times 10^{3} \mathrm{~m}^{3}$ (CARVALHO, 1971). Em relação a este valor, note-se que foi obtido a partir de um volume não fechado, pois houve algum movimento de areias para sul, pelo que o valor real para esse períododeve estar mais próximo de $10^{6} \mathrm{~m}^{3} / \mathrm{ano}$ (ABECASIS et al., 1962). Por outro lado, é necessário salientar que a análise da ondulação revelou que dos 5 anos do período considerado, 4 foram mais energéticos que o normal, em particular o de 1965-66, o que permite concluir que o caudal sólido médio do período analisado foi superior ao caudal médio anual obtido para um grande número de anos (Consulmar, 1973). A partir de 1966 os levantamentos topo-hidrográficos passaram a abranger uma área mais restrita mas suficientemente vasta para se poder concluir que na zona adjacente ao molhe norte se atingiu uma situação de equilíbrio dinâmico; isto significa que entre 1966e 1969, consideráveis volumes de areia terão transposto para sul a cabeça do molhe norte, quer para se acumularem na barra e anteporto, quer ultrapassando definitivamente a embocadura.

CAStanho et al. (1974) admitem um valor de $10^{6} \mathrm{~m}^{3} /$ ano para a deriva litoral junto a Aveiro. OLIVEIRA et al. (1982), com base na análise de coberturas de fotografia aérea, consideram que este valor estará subestimado e que a capacidade de transporte potencial da agitação marítima na costa ocidental poderá atingir os $2 \times 10^{6} \mathrm{~m}^{3} /$ ano; note-se que, segundo estes autores, com a construção dos molhes do porto de Aveiro o volume total acumulado, incluindo a praia submersa e os montantes da extracção de areia, atingiu $20 \times 10^{6} \mathrm{~m}^{3}$ de 1950 a 1978 (700 $\left.\times 10^{3} \mathrm{~m}^{3} / \mathrm{ano}\right)$. Recentemente, a extracção de areias da praia em S. Jacinto (Porto de Aveiro) atingiu um valor máximo de $590 \times 10^{3} \mathrm{~m}^{3} / \mathrm{ano}$ em 1990, mas desde 1994 tem vindo a manter-se em cerca de $300 \times 10^{3} \mathrm{~m}^{3} / \mathrm{ano}$; contudo, os montantes das extracções de areia na manutenção permanente dos fundos dos canais portuários e embocadura (sem reposição a sotamar) são elevados $\left(517-688 \times 10^{3} \mathrm{~m}^{3 /}\right.$ /ano, de 1994 a 1996)*.

\footnotetext{
* Estes montantes não incluem outros tipos de dragagem, de areias, para alteração das condiçōes existentes (alteração de cotas, dragagem de bacias de manobra, etc.) ou a dragagem de fundos lodosos.
} 
Os montantes de areia extraída na praia e embocadura do Porto da Figueira da Foz apresentaram um valor médio de cerca de $420 \times 10^{3} \mathrm{~m}^{3} / a$ no nos últimos dez anos; admitimos que o montante realmente extraído será um pouco inferior ao caudal sólido médio em deriva no estrão da Figueira da Foz. Com efeito a extracçãode cerca de $50 \times 10^{3} \mathrm{~m}^{3} / \mathrm{mês}$ de areias marinhas na praia, atingidos em 1993, ocasionou grande erosão local; note-se que, dada a ausência de meios de pesagem, os volumes são obtidos por estimativa dos veículos de carga podendo o montante real extraído estar subestimado até $30 \%$. O facto de não se ter verificado recuo erosivo no sector Cabo Mondego-Tocha desde 1957 a 1990 (Ferreira, 1993), situação que se continuou até $1998^{*}$, significa que este troço manteve a sua orientação face ao clima de agitação marítima, pelo que o caudal sólido que o percorre (e que ultrapassa para sul o Cabo Mondego) continuará a ser praticamente o mesmo, admitindo que o clima médio anual de agitação marítima não se alterou nas últimas duas ou três décadas (I. Mota Oliveira, 1998, comun. pessoal).

Em conclusão, dado que na última década ainda não se verificou tendência de recuo no sector Praia de Costinha-Cabo Mondego, admitimos um valor médio de $1,5 \times 10^{6} \mathrm{~m}^{3} /$ ano para a deriva litoral de areia que, a partirde norte, alimenta o troço Cabo Mondego-Figueira da Foz.

\section{Relação entre erosão costeira e extracção de areias}

Éevidente a relação entre a deriva litoral, resultante das características da agitação marítima, e a alimentação das praias. Interessa também analisar em que medida as situações concretas de remoçãode areias do trânsito sedimentar condicionam a evolução das praias do sector em apreço.

Nos últimos cinco anos ocorreram várias situações erosivas na faixa de praia a norte da embocadura do Mondego. Reveste-se de interesse a quantificação do limite máximo de extracção na praia, que corresponde a definir o volume que é possível retirar do estrão sem causar progressiva erosão no local e a barlamar da deriva litoral predominante. Desde logo há que considerar os seguintes condicionalismos ao balanço sedimentar:

- Variabilidade sazonal da intensidade, orientação e período da ondulação;

- Grande variabilidade plurianual dos regimes de ondulação;

- Variabilidade sazonal e plurianual dos influxos arenosos de origem fluvial, cada vez menores;

\footnotetext{
* No reconhecimento aéreo que efectuámos na baixa-mar de maré viva em $30 / 01 / 98$ constatámos que a larga faixa de praia a norte do Cabo Mondego só apresentava contínua arriba erosiva, talhada na duna frontal, para norte da Praia de Costinha.
}

- Progressivo aumento do défice sedimentar na deriva litoral (que resulta principalmente de causas antrópicas).

$\mathrm{Na}$ área analisada é possível relacionar situações recentes de recuo da linha de costa e criação de bermas erosivas na praia da Figueira da Foz (Fig. 1), com a sobre-extracção de areia na praia:

- Na transição 1992-1993 a extracção atingiu valores médios próximos de $40 \times 10^{3} \mathrm{~m}^{3} / \mathrm{mês}$, verificando-se grande recuo erosivo na Praia da Figueira (com destruição de um apoio de praia em Janeiro de 1993), sendo atingidos $50 \times 10^{3} \mathrm{~m}^{3} / \mathrm{mês}$ em Abril de 1993, data em que se estabeleceram restrições à extracção. Tratou-se de um ano com clima de agitação marítima próximo da média, sendo a sobre-escavação local resultante da extracção de volumes que ultrapassaram o natural afluxo sedimentar.

- No $1^{\circ}$ semestre de 1996 assistiu-se a um enorme rebaixamento na área de extracção de areias (Foto 2), com propagação para norte da berma erosiva e redução drástica da areia extraída por draga de sucção na barra submersa exterior. Neste caso, apesar das sucessivas reduções dos volumes explorados, a sobre-extracção resultou principalmente de condições de agitação marítima anómalas, com rumos médios mais rodados para $\mathrm{W}$ que não permitiram a persistente transposição para sul do Cabo Mondego das areias litorais alimentadoras, reduzindo ou mesmo anulando temporariamente o caudal sólido através do Cabo Mondego, sem afectar significativamente a capacidade de transporte potencial no trecho imediatamente a sul. Nestas condições, a capacidade de transporte da agitação marítima não é saturada por alimentação em deriva de norte, indo reduzir o défice sedimentar por erosão da praia a sotamar.

Em síntese, para além da movimentação longitudinal e transversal de areia no litoral ser muito variável de ano para ano, a retirada de volumes arenosos em qualquer ponto do circuito da linha de costa, já frequentemente deficitário, aumentará a tendência erosiva nas praias adjacentes, em particular nas que se situam a sotamar da deriva dominante.

\section{A evolução da faixa de praia desde 1995 a meados de 1998}

\section{Situação em 1995}

Até finais de 1995, a faixa de praia deste sector costeiro apresentou as características habituais, como registámos no reconhecimento aéreo efectuado na baixa-mar de maré viva em 12/08/95. Do Cabo Mondego ao Forte de Buarcos, a praia apresenta pequena largura e espessura de areia sobre o substrato mesozóico, mas para sul de Buarcos a largura é 
considerável. O perfil reflectivo das praias é dominante, transitando para dissipativo em condições de agitação enérgica ou em locais que sofram uma tendência erosiva. Segundo CunHa et al. (1997b) junto ao Cabo Mondego os sedimentos das praias são fundamentalmente areias muito grosseiras e areão; ocorrem também bolsadas de cascalho, quase sempre condicionadas por afloramentos rochosos na praia baixa e pré-praia. Mais para sul as areias são grosseiras a médias, ricas em quartzo e bioclastos. A praia submersa apresenta areia fina a muito fina, micácea, bem calibrada e unimodal.

\section{O importante temporal de Janeiro de 1996}

Durante a madrugada do dia 7 de Janeiro de 1996, o mau tempo fez-se sentir com grande violência, com muita chuva e rajadas de vento forte a provocarem a queda de árvores e andaimes na área urbana da Figueira da Foz. Os efeitos mais desastrosos verificaram-se no litoral, com ondas enormes a galgar a avenida em volta do Forte de Buarcos e a atirar com barcos e pedras para a faixa de rodagem. Ocorreu galgamento oceânico na praia alta da Figueira da Foz, com acesso pela zona de exploração de areia junto ao molhe norte, provocando grande inundação da antepraia e atingindo a base da torre do relógio (Foto 1). A maioria dos "apoios de praia" situados na praia alta sofreram estragos sendo o restaurante "O Bote", mais uma vez, seriamente destruído e ficando parte do seu recheio espalhado pela praia. A praia da Figueira da Foz foi fortemente fustigada pelo mar, verificando-se uma tão grande erosão que impediu a extracção de areia na praia durante vários dias. Este temporal produziu significativa erosão no litoral português, ficando muito marcado no perfil transversal das praias, evidenciado, nomeadamente, por ALMEIDA \& AmARal (1996) que estudaram a evolução das praias do sector Quiaios-Gala durante o inverno de 1995/96 através da realização periódica de perfis topográficos transversais à praia-duna.

A evolução de Maio de 1996 a Novembro de 1997

Tendo-se detectado significativa erosão das praias deste sector durante o inverno de 1995/96, que se continuou nos meses seguintes, realizámos uma pormenorizada monitorização através de um periódico registo fotográfico (no terreno e aéreo, em especial dos locaiscom rápida evolução topográfica), cartografia de pormenor e execução de perfis topográficos transversais à faixa de praia. No estudo feito até inícios de 1997, foi prevista a continuação da erosão para o troço Buarcos-Figueira da Foz (CunHA et al., $1997 \mathrm{a}, 1997 \mathrm{~b}$ ). Neste sentido continuou-se a monitorização durante 1997 e 1998, tendosido possível acompanhar pormenorizadamente a intensa erosão na praia de Buarcos-Figueira da Foz.
Durante 1996 o recuo erosivo afectou o sector imediatamente a sul do Cabo Mondego, estendendo-se progressivamente para sul até atingir as imediações do Forte de Buarcos. Devido à progressiva remoção de areia, o prisma arenoso de praia do sector TeimosoBuarcos, com uma largura original de $40-90 \mathrm{~m}$ (situação anterior a 1995), sofreu $2,5 \mathrm{~m}$ de rebaixamento máximo (até atingir o substrato rochoso). Seguidamente deu-se o desmoronamento do enrocamento de suporte da estrada marginal oceânica, numa extensão de 2 $\mathrm{Km}$, incluindo troços da faixa de estacionamento e rodagem. Nesta fase da evolução erosiva, já muito avançada para o interior e com o substrato rochoso a descoberto, os estragos na marginal ocorriam na preia-mar, especialmente em maré viva ou com mais energética ondulação de $\mathrm{W}$, embora a maior perda de areia se tenha verificado geralmente em situação de fraca ondulação. Calculámos que a erosão do areal no estrão entre o Cabo Mondego o o Forte de Buarcos, desde Outubro de 1995 a Novembro de 1996, correspondeu à remoção de aproximadamente $0,4 \times 10^{6} \mathrm{~m}^{3} \mathrm{de}$ areia; em igual período (14 meses) a areia extraída na praia e barra foi de $0,46 \times 10^{6} \mathrm{~m}^{3}$. No areal do sector Teimoso-cemitério de Buarcos, o recuo da linha de costa desde meados de Outubro de 1995 a meados de Julho de 1996 ( 9 meses) foi de $20-45 \mathrm{~m}$ e, posteriormente, até meados de Novembro de 1996 (4 meses) de mais $20 \mathrm{~m}$. Descrevem-se, seguidamente, alguns aspectos da evolução costeira:

- Nos meses seguintes ao período de temporal, ocorreu importante modificação da faixa de praia do Cabo Mondego a Buarcos devido à progressiva remoção do prisma arenoso que cobria o substrato rochoso mesozóico.

- A partir de inícios de Maio de 1996 já era claramente visível na praia média uma berma erosiva, que se iniciou entre o Teimoso e o restaurante Costa. Principalmente nos meses de Maio, Setembroe Outubro de 1996, o degrau erosivo foi-se entalhando na praia alta e estendendo também progressivamente para SE até atingir a área a oeste do Forte de Buarcos.

- Em meados de Julho de 1997 já 2/3 da largura do areal para NW do cemitério de Buarcos estavam erodidos e observava-se uma arriba que atingia cerca de $2 \mathrm{~m}$ de altura (Foto 2 ). $\mathrm{Na}$ área concessionada para a extracção de areia na praia (zona da relógio) verificouse também um importante rebaixamento de cota com exposição dos destroços de uma embarcação (Foto 3) e a continuação do recuo da linha de costa, com a propagação para norte da berma erosiva de praia, o que obrigou a duas reduções no quantitativo máximo mensal de extracção (em Junho e Setembro de 1996). Os destroços mantiveram-se à vista até meados de Dezembro, data em que voltaram a ficar completamente enterrados; posteriormente, só voltaram a aflorar em meados de Fevereiro de 1997. 
- Em finais de Setembro de 1996 a arriba no areal do troço a NW de Buarcos atingia a frente da escadaria junto à antiga fábrica de cimento; junto ao cemitério de Buarcos a erosão atingia a base do enrocamento da marginal e ocorria o desmoronamento da adjacente escadaria de acesso à praia.

- Em Novembro de 1996 encontrava-se em escorregamento todo o enrocamento entre o Teimoso e o cemitério de Buarcos; caía o passeio da marginal junto à antiga fábrica de cimento e, mais para SE, a arriba erosiva "mordia" o enrocamento do estacionamento frente ao restaurante Tamargueira (Fig. 1).

\section{A evolução de Dezembro de 1996 a Julho de 1998}

No mês de Dezembro de 1996 o mar voltou a estar muito agitado (altura média de $4 \mathrm{~m}$ ), com rumos deondulação predominando de SW e com significativos rumos de W; a partir de Buarcos verificou-se alguma propagação para sul da berma erosiva no areal.

A partir de 5 de Janeiro de 1997 ocorreu uma intensa erosão na praia de Buarcos, afectando progressivamente para sul, em especial a área imediatamente a sul da curva da estrada junto ao Forte de Buarcos. O recuo da linha de costa atingiu grandes proporções em frente à povoação de Buarcos, impedindo o acesso à praia dos barcos de pesca, pois o degrau erosivo no areal atingiu 1,5 m de altura. No dia 11 de Janeiro de 1997, na curva do Forte de Buarcos, foi feita a primeira colocação de grandes blocos de calcário (trazidos de Alcobaça!), tentando impedir o desabamento da faixa de rodagem (que acabou por ocorrer parcialmente); posteriormente, sucederam-se mais deposições de blocos em intervenções de urgência. Por esta data, já toda a praia entre Buarcos e o molhe norte apresentava uma contínua berma erosiva que se foi agravando durante Fevereiro de 1997, apesar de nos dias 20 a 23 deste mês uma forte ondulação de $\mathrm{NW}$ (que atingiu $4 \mathrm{~m}$ ) ter gerado uma intensa deriva litoral para sul que assoreou significativamente a barra do porto. Na $1^{a}$ quinzena de Fevereiro de 1997 caíu o passeio da marginal junto ao cemitério de Buarcos, apesar da deposição na arriba de grandes blocos de calcário (Foto 4); a cabeça do molhe exterior sul encontrava-se em reparação. Pelo contrário, imediatarnente a norte do Cabo Mondego, a importância dos rumos de W deve ter sido responsável por uma invulgar acumulação de areia na praia submarina, expressa por uma rebentação mais longe devido a uma plataforma de dissipação de energia muito mais extensa do que é habitual.

De Março a fínais de Maio de 1997 continuou a tendência de recuo na Praia de Buarcos (Foto 5); no início de Maio os "apoios de praia" neste areal protegeram as suas frentes viradas ao mar, com grandes montes de areia. Contrariamente ao que é habitual, a situação ainda se continuou a agravar no mês de Junho. Em Junho de 1997 o substrato rochoso de Buarcos ao Cabo Mondego continuava quase completamente exposto e já desmoronado um longo troço da faixa de estacionamento da marginal, tendose iniciado as obras de reconstrução do enrocamento; continuava o recuo erosivo no areal de Buarcos.

O reconhecimento aéreo que efectuámos na baixamar de maré viva em 17/07/97 documentou a exposição do substrato geológico entre o Cabo Mondego e o Forte de Buarcos, bem como a erosão no areal de Buarcos e no areal de Quiaios. Também, de acordo com informações de pescadores, em meados de Julho 1997 não existia a faixa de areia submersa que podia atingir 2 $m$ de espessura, que habitualmente no verão cobria o substrato rochoso em frente à enseada de Buarcos.

No posterior reconhecimento aéreo efectuado na baixa-mar de maré viva em 30/01/98 constatámos que a larga faixa de praia a norte do Cabo Mondego apresentava arriba erosiva talhada na duna frontal, excepto no sector de Murtinheira-Quiaios-Costinha que já tinha recuperado areia; o litoral a sul do Cabo Mondego evidenciava uma pequena acumulação de areia que deve ter resultado do curto período com forte ondulação de $N W$ verificado durante a $1^{\circ}$ semana de Janeiro de 1998 (Foto 6).

No seguimento de diligências da Câmara Municipal da Figueira da Foz e de contactos com o Ministério do Ambiente e a Junta Autónoma do Porto da Figueira da Foz, a extracção de areia na praia da Figueira da Foz parou desde 6 de Março de 1998.

Emresumo, após a completa exposição do substrato geológico mesozóico frente à estrada entre o Cabo Mondego e Buarcos e inibição do recuo local pela deposição, em intervenções de imergência, de enormes volumes de blocos, a continuação do défice sedimentar litoral durante 1997 e 1998 resultou na propagação da evolução erosiva ao troço arenoso situado imediatamente para SE (Buarcos-molhe norte). Na praia de Buarcos, junto ao forte, de finais de Setembro de 1996 a Setembro de 1997 o recuo foi de $14 \mathrm{~m}$, e até finais de Abril de 1998 mais $10 \mathrm{~m}$ de recuo (em 6 meses); posteriormente, de Maio a Julho desse ano, verificouse um início de tendência para recuperação de areia. Com base em perfis topográficos de praia, avaliou-se que de finais de Setembro de 1996 a princípios de Junho de 1998 ocorreu a erosão de $1143 \times 10^{3} \mathrm{~m}^{3}$ de areia; em igual período (20 meses) a extracção de areia na praia e barra foi de $701 \times 10^{3} \mathrm{~m}^{3}$.

\section{Áreas adjacentes}

Imediatamente a norte do Cabo Mondego, a monitorização da Praia da Murtinheira mostrou grande recuo da linha de costa durante Dezembro de 1997, avanço em Janeiro, recuo em Fevereiro e avanço de Março a Junho de 1998 (recuperando a posição 
inicial); junto ao posto da GNR esta oscilação atingiu os $60 \mathrm{~m} ; 1 \mathrm{~km}$ mais a sul, junto da falésia, a oscilação foi maior $(88 \mathrm{~m})$ e ganhou areia (em Abril a ondulação de NW e W foi geralmente superior a $3 \mathrm{~m}$ de altura).

A praia arenosa imediatamente a sul do campo de esporões da Cova evidenciou um contínuo recuo: de finais de Setembro de 1996 a inícios de Fevereiro de 1998 (16 meses) a arriba talhada no cordão dunar recuou $5 \mathrm{~m}$ (taxa média de $-3,8 \mathrm{~m} / \mathrm{ano}$ ); de Fevereiro a finais de Maio de 1998 recuou $0,8 \mathrm{~m}$ (taxa média de $-2,4 \mathrm{~m} / \mathrm{ano}$ ).

A partir de finais de Junho de 1998 iniciou-se de uma dragagem para aprofundar até à cota $-7 \mathrm{~m} \mathrm{ZH}$ todo o canal estuarino a jusante da ponte da Figueira da Foz, incluindo o anteporto e barra do porto da Figueira da Foz, efectuando-se o quebramento de rocha e a remoção de, aproximadamente, $1.300 \times 10^{3} \mathrm{~m}^{3}$ de sedimentos que irão ser largados junto da costa em frente do hospital na Cova-Gala.

\section{Características da agitação marítima}

\section{Os temporais de Dezembro de 1995 a Janeiro de 1996}

Ocorreu grande agitação marítima em Dezembro de 1995 e Janeiro de 1996. Durante a madrugada do dia 7 de Janeiro, a agitação caracterizou-se por ondulação de WNW que atingiu $9,3 \mathrm{~m}$ de altura às $0 \mathrm{~h}$; das $3 \mathrm{~h}$ às $6 \mathrm{~h}$ ocorreu avaria do ondógrafo do Cabo Mondego, tendo-se registado um novo máximo da agitação marítima às $9 \mathrm{~h}(\operatorname{com} 7,5 \mathrm{~m}$ e N292 de rumo) e um progressivo decréscimo (às $12 \mathrm{~h}$ já apresentava $6,7 \mathrm{~m}$ e rumo de $\mathrm{N} 285^{\circ}$ ).

Ainda no espaço de uma semana, na madrugada do dia 12 de Janeiro de 1996, o mar voltou a estar agitado. Apresentou ondas ao largo com 7 a $9 \mathrm{~m} \mathrm{de}$ altura e rumo médio de WSW, de acordo com a descrição paramétrica do estado do mar para a zona da Figueira da Foz adquirida ao Instituto Nacional de Meteorologia e Geofísica.

\section{A variação na agitação marítima}

Nas tabelas 3, 4 e 5, bem como nas figuras 2 e 3 , apresenta-se a variação mensal e anual das características da ondulação. Devido aos largos períodos sem registo, por avaria do ondógrafo, nos dados disponibilizados pelo Instituto Hidrográfico relativos a 1995 e 1996 (Fig. 2), complementou-se a análise com a compilação das previsões diárias das condições de agitação, pelo Instituto de Meteorologia (Fig. 3), obtidas por modelo matemático baseado no regime de ventos. A comparação dos dados, apesar dos diferentes métodos de aquisição e significados, revela uma elevada concordância nos valores mensais e anuais (Tab. 5). Esta será, aliás, uma via a explorar para colmatar o défice de informações sobre ondulação que se tem verificado nos anos mais recentes, em particular após a desactivação do ondógrafo do Cabo Mondego em Janeiro de 1996. Nesse sentido, também elaborámos uma folha de registo da ondulação que, em colaboração com a Capitania do Porto da Figueira da Foz, desde 1997 tem vindo a ser preenchida diariamente com a observação do mar no farol do Cabo Mondego.

A comparação com o ano de 1995 , no que se refere à frequência da ondulação de We SW (minoritária no cômputo anual), permite verificar que em 1996 ela foi (Tabela 4):

- Muito maior nos meses de Janeiro e Março;

- Maior em Setembro e Dezembro;

- Ligeiramente menor em Fevereiro, Abril, Maio, Outubro e Novembro;

Ainda relativamente a 1995, a altura da ondulação em 1996 foi (Tabela 5):

- Muito maior no mês de Janeiro;

- Maior nos meses de Maio e Junho;

- Menor nos meses de Fevereiro, Março, Abril, Julho e Setembro.

Por outro lado, verificou-se em 1996 uma certa tendência da ondulação de oeste ter genericamente uma maior altura, sucedendo o contrário com a de NW. Globalmente, nos últimos anos a ondulação teve uma altura média idêntica: $1995-2,2 \mathrm{~m} ; 1996$ - 2,2 m; 1997 -2,0; 1998 (dados só até Julho) - 2,0 m; valor médio do período 1989/97 - 2,1 m (Tabela 5).

Contudo, verificou-se que nos três últimos anos o rumo médio anual foi mais rodado para oeste: 1996 - N301; 1997 - N285; 1998 (dados só até Julho) $\mathrm{N} 292^{\circ}$; o rumo médio anual no período $1989-97$ (9 anos) apresentou uma média de $\mathrm{N} 305^{\circ}$. Esta variação resulta das características mensais dos vários rumos da ondulação também terem variado nos últimos anos relativamente ao que é habitual; comprovou-se uma progressiva diminuição na frequência dos rumos de NW e um aumento dos de SW. Relativamente às médias mensais no período 1989-97, verifica-se que a altura da ondulação tem um desvio padrão muito maior do que o associado ao rumo.

Na climatologia de Portugal Continental, segundo dados do Instituto de Meteorologia, o ano de 1995 foi, globalmente, o mais quente desde 1931. O ano de 1995, quanto à precipitação, foi caracterizado pela continuação da situação de seca até Agosto. A partir de Outubro a situação alterou-se radicalmente. As quantidades de precipitação registadas nos meses de Novembro e Dezembro permitem classificá-los de chuvoso e extremamente chuvoso, respectivamente. Os anos de 1996 a 1998 regeram-se por contextos climatéricos fora do habitual (anos mais húmidos), 
com o designado Anticiclone dos Açores afastado da sua posição típica e Portugal Continental a ser frequentemente condicionado por depressões e pela passagem das respectivas superfícies frontais; ainda recentemente foi notória a grande precipitação nos meses de Novembro-Dezembro de 1997 e Janeiro de 1998.

\begin{tabular}{|c|c|c|c|c|c|c|c|c|c|c|c|c|c|c|}
\hline f. $: 00 z$ & 1995 & H & w & $y$ & SW & S $\quad$ SE & LEIXC & ว996 & A & wW & w & sw & s & SE \\
\hline \multirow{3}{*}{ JAK } & $x$ obs. & 2 & 82 & 14 & 1 & & \multirow{3}{*}{$S Z H$} & $x$ obs. & & & & & & \\
\hline & HA (a) & 2.8 & 3.1 & 2.6 & & & & Hin (a) & & & & & & \\
\hline & $\operatorname{Tin}(s)$ & 6.3 & 7.7 & 8.0 & & & & 7 in (s) & & & & & & \\
\hline \multirow{3}{*}{ FEV } & Tobs. & & 86 & 9 & & & \multirow{3}{*}{ fEV } & $\bar{x}$ obs. & & & & & & \\
\hline & $\operatorname{Han}(\mathrm{m})$ & & 3.5 & 2.5 & & & & Hin (m) & & & & & & \\
\hline & Tm $(s)$ & & 9.2 & 7.6 & & & & in (s) & & & & & & \\
\hline \multirow{3}{*}{ MUR } & $\not$ obs. & & 160 & & & & \multirow{3}{*}{ MAR } & $x$ ots. & \& & 61 & $4 \theta$ & 18 & & \\
\hline & $\operatorname{Hin}(\mathrm{A})$ & & 3.6 & & & & & Hin $(m)$ & & 2.6 & 1.6 & 2.2 & & \\
\hline & $\operatorname{Im}(s)$ & & 0.1 & & & & & $T \operatorname{TS}(s)$ & & 7,9 & 6.5 & 8.4 & & \\
\hline \multirow{3}{*}{$A B R$} & $\bar{Y}$ obs. & & & & & & \multirow{3}{*}{ ABR } & $Y$ obs. & 7 & si & 38 & ? & & \\
\hline & $\operatorname{Han}(n)$ & & & & & & & $\operatorname{H\rightarrow n}(n)$ & 8.5 & 1.8 & 2.0 & 2.5 & & \\
\hline & Tin (s) & & & & & & & $\operatorname{IA}(s)$ & 5.5 & 6.6 & 7.8 & 6.1 & & \\
\hline \multirow{3}{*}{ Mas } & $z$ obs. & & & & & & \multirow{3}{*}{ YAI } & y obs. & 18 & 42 & 28 & 12 & & \\
\hline & $\sin (n)$ & & & & & & & $\operatorname{Him}(\mathrm{m})$ & 2.3 & 1.8 & 1.7 & 1.8 & & \\
\hline & TAR (s) & & & & & & & In $(s)$ & 7.4 & 6.2 & 6.3 & 6.0 & & \\
\hline \multirow{3}{*}{ SNH } & מ obs. & & & & & & \multirow{3}{*}{ JUK } & $\gamma_{\text {obss. }}$ & 6 & 72 & 22 & & & \\
\hline & HIm (m) & & & & & & & Ha $(\mathrm{mi})$ & & 2.0 & 1.2 & & & \\
\hline & $7 \mathrm{~m}(\mathrm{~s})$ & & & & & & & $T \operatorname{Ts}(s)$ & & 0.2 & 5.6 & & & \\
\hline \multirow{3}{*}{ JUL } & $\bar{x}$ obs. & 11 & 78 & it & Ki & & \multirow{3}{*}{ sut } & $\bar{y}$ obs. & 3 & 95 & 2 & & & \\
\hline & $\tan (n)$ & 9.3 & 1.4 & 1.3 & & & & $8 \pi(x)$ & & 1.4 & & & & \\
\hline & Trm (s) & 5.0 & 5.6 & 5.0 & & & & $\operatorname{Im}(s)$ & & 5.5 & & & & \\
\hline \multirow{3}{*}{$A \in O$} & z ebs. & 6 & 38 & 6 & & & \multirow{3}{*}{160} & $x$ obs. & 3 & 87 & 9 & & 81 & \\
\hline & Hit (n) & 1.1 & 1.6 & 1.0 & & & & $\mathrm{kn}(\mathrm{m})$ & 1.3 & $\overline{1.4}$ & 1.4 & & & \\
\hline & $\operatorname{Tm}(s)$ & 5.7 & 5.7 & 5.0 & & & & in $(s)$ & 4.8 & 6.0 & 6.6 & & & \\
\hline \multirow{3}{*}{ SET } & ats. & 12 & 2 & $\overline{2 \hat{k}}$ & (1 & & \multirow{3}{*}{ SET } & $\bar{x}$ cobs. & & 74 & 25 & 4 & & 4 \\
\hline & $H_{m}(\mathrm{~m})$ & 9.6 & 1.8 & 1.5 & & & & $\operatorname{Rn}(m)$ & & 1.7 & 8.4 & & & \\
\hline & $\ln (s)$ & 5,4 & 6.1 & 5.8 & & & & $\operatorname{Ir}(s)$ & & 6.8 & 5.7 & & & \\
\hline \multirow{3}{*}{ OUI } & $x$ obs. & & 76 & 21 & 4 & & \multirow{3}{*}{ DUT } & 8 obs. & 4 & 74 & 24 & 1 & & \\
\hline & him (m) & & 1.9 & 1.9 & 2.2 & & & Hin (m) & & 2.3 & 2.4 & & & \\
\hline & $\operatorname{Tin}(s)$ & & 7.6 & 7.8 & 5.4 & & & $\operatorname{Tn}(s)$ & & 7.7 & 8.0 & & & \\
\hline \multirow{3}{*}{ ror } & 4 obs. & 1 & 58 & 32 & 8 & 4 & \multirow{3}{*}{ nov } & 7 obs. & 1 & 78 & 22 & & & \\
\hline & $\mathrm{Rm}(n)$ & & 2.3 & 1.9 & 2.4 & & & $\operatorname{Him}\{m\}$ & & 2.9 & 1.8 & & & \\
\hline & $I_{\text {I }}(s)$ & & 7.2 & 6.9 & 6.5 & & & In $(s)$ & & 7.5 & 7.5 & & & \\
\hline & 7 obs. & 51 & 39 & 53 & 7 & & & $x$ obs. & & 32 & 53 & 15 & व & \\
\hline DEZ & $\mathrm{Hm}$ (m) & & 3.4 & 3.1 & $2 . \overline{6}$ & & DE2 & Hin $\langle(n)$ & & 2.0 & 2.6 & 2.5 & & \\
\hline & $\operatorname{Tn}\{s\}$ & & 7.6 & 7.2 & 6.7 & & & $7 \mathrm{~m}(\mathrm{~s})$ & & 6.7 & 7.5 & 6.3 & & \\
\hline & Tobs. & 4.0 & 72.2 & 21.1 & 2.6 & $x .1$ & & " obs. & 2.6 & 66.7 & 26.5 & 3.9 & .2 & $x .1$ \\
\hline GLOBAL & $\mathrm{H} / \mathrm{m}(\mathrm{m})$ & 1.5 & 2.3 & 2.3 & 2.3 & & GLCBAL & $\operatorname{tgn}(n)$ & 1.7 & 2.0 & 2.8 & 2.3 & & \\
\hline & Tा (s) & 5.3 & 7.1 & 6.9 & 6.3 & & & ID (s) & 5.7 & 6.7 & 7.2 & 6.2 & & \\
\hline
\end{tabular}

Tabela 3 - Caracterização mensal da ondulação ao largo, na costa ocidental de Portugal Continental ( $\mathrm{Hm}$ - altura média; Tm - período médio). Dados disponibilizados pelo Instituto Hidrográfico.

\begin{tabular}{|c|c|c|c|c|c|c|c|c|}
\hline Mês & Ondulação & 19951M & $19951 \mathrm{H}$ & $19961 \mathrm{M}$ & $19961 \mathrm{H}$ & $1997 \mathrm{IM}$ & $1998 \mathrm{IM}$ & $1989-971 \mathrm{M}$ \\
\hline \multirow[t]{2}{*}{ Janeiro } & Rumo & 312 & 307 & 289 & $*$ & 279 & 286 & $304 \pm 12$ \\
\hline & Aliura & 2.8 & 3,01 & 4.1 & * & 2,4 & 2.7 & $2,7 \pm 0,7$ \\
\hline \multirow[t]{2}{*}{ Fevereiro } & Rumo & 303 & 304 & 306 & * & 286 & 266 & $306 \pm 9$ \\
\hline & Altura & 3.3 & 3,39 & 2.6 & $*$ & 2.4 & 1.8 & $2.6 \pm 0.5$ \\
\hline \multirow[t]{2}{*}{ Março } & Rumo & 315 & $*$ & 296 & 281 & 287 & 298 & $306+10$ \\
\hline & Altura & 2.7 & * & 2.2 & 2,16 & 1,8 & 1.7 & $2,4 \pm 0,4$ \\
\hline \multirow[t]{2}{*}{ Abril } & Rumo & 299 & $*$ & 305 & .303 & 289 & 293 & $306 \pm 8$ \\
\hline & Altura & 2,0 & * & 2,0 & 1,84 & 1.4 & 3,0 & $2.2 \pm 0,4$ \\
\hline \multirow[t]{2}{*}{ Maio } & Rumo & 298 & $*$ & 298 & 299 & 267 & 301 & $299 \pm 13$ \\
\hline & Aliuri & 1,8 & * & 1,9 & 1,90 & 1,9 & 1.5 & $1,8 \pm 0,2$ \\
\hline \multirow[t]{2}{*}{ Junho } & Rumo & 314 & $*$ & 315 & $3 I I$ & 289 & 300 & $311 \pm 8$ \\
\hline & Altura & 1.4 & $*$ & 1.5 & $*$ & 1,8 & 1.5 & $1.6 \pm 0.2$ \\
\hline \multirow[t]{2}{*}{ Julho } & Rumo & 315 & 315 & 315 & 318 & 314 & & $315 \pm 0$ \\
\hline & Altura & 1.4 & 1.36 & 1,3 & 1.41 & 1.4 & & $1.5 \pm 0.1$ \\
\hline \multirow[t]{2}{*}{ Agosto } & Rumo & 315 & 3.16 & 312 & 315 & 302 & & $313 \pm 4$ \\
\hline & Altura & 1,5 & $1,3,3$ & 1.5 & 1,43 & 1,5 & & $1,5 \pm 0,1$ \\
\hline \multirow[t]{2}{*}{ Setembro } & Rumo & 314 & 314 & 309 & 303 & 308 & & $310 \pm 4$ \\
\hline & Altura & 1.9 & 1.73 & 1,5 & 1,60 & 1,3 & & $1,7 \pm 0,2$ \\
\hline \multirow[t]{2}{*}{ Outubro } & Rumo & 293 & 304 & 298 & 307 & 270 & & $302 \pm 14$ \\
\hline & Altura & 2,2 & 1.94 & 2.1 & 2,34 & 1,9 & & $2,1 \pm 0,3$ \\
\hline \multirow[t]{2}{*}{ Novembrl } & Rumo & 290 & 296 & 309 & 307 & 274 & & $300 \pm 11$ \\
\hline & Altura & 2,2 & 2,18 & 2.2 & 2,67 & 3,4 & & $2.56 \pm 0.4$ \\
\hline \multirow[t]{2}{*}{ Dezembra } & Rumo & 292 & 286 & 264 & 279 & 272 & & $295 \pm 16$ \\
\hline & Altura & 3.0 & 2,76 & 32 & 2,40 & 2.8 & & $2,8 \pm 0,5$ \\
\hline \multirow[t]{2}{*}{ Anual } & Rumo & 305 & 306 & 301 & 303 & 285 & 222 & 305 \\
\hline & Altura & 2.2 & 2,25 & 2.2 & 1,98 & 2,0 & 2,0 & 2,1 \\
\hline
\end{tabular}

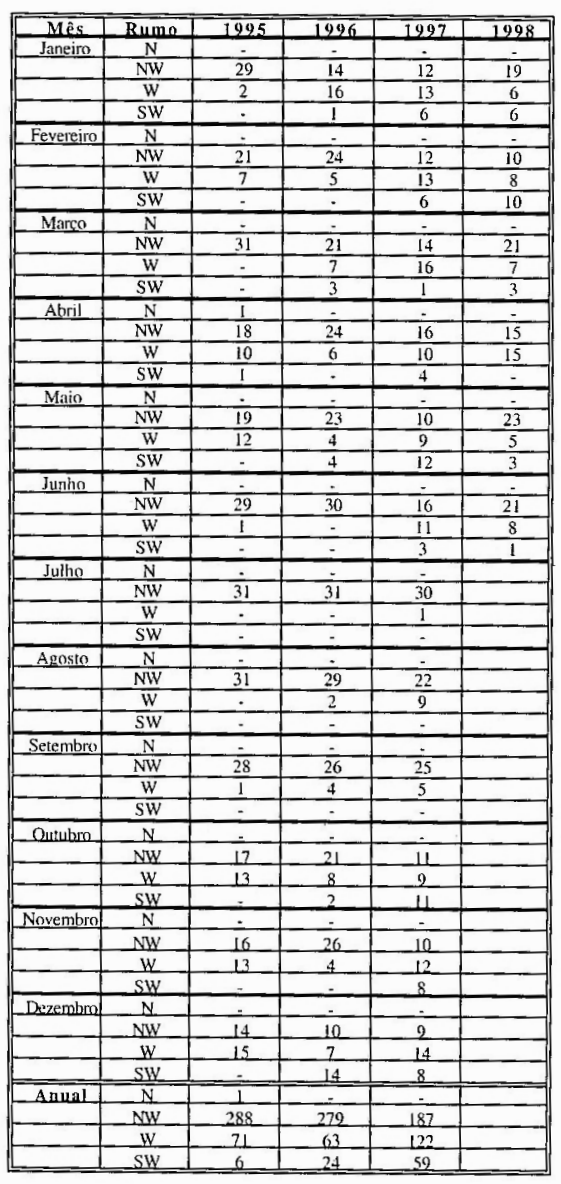

Tabela 4 - Número de dias, por mês e ano, com cada rumo dominante ao largo da costa da Figueira da Foz. Valores compilados a partir das previsões diárias do Instituto de Meteorologia, apresentadas em jornais diários.

Tabela 5 - Médias mensais e anuais do rumo (graus) e altura (m) da ondulação dos anos de

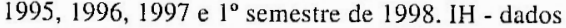
do Instituto Hidrográfico (* - média não significativa por falta de registos; 1995 - Cabo Mondego; 1996 - Leixões); IM - previsões diárias do Instituto de Meteorologia para à costa ocidental portuguesa, a norte do Cabo Carvoeiro. 
FFOZJ - SÉRIE TEMPORAL DE HMO

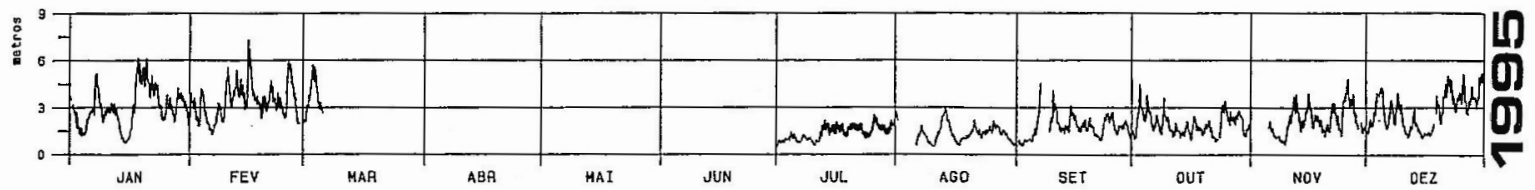

LEIXÕES D - SÉRIE TEMPORAL DE HMO
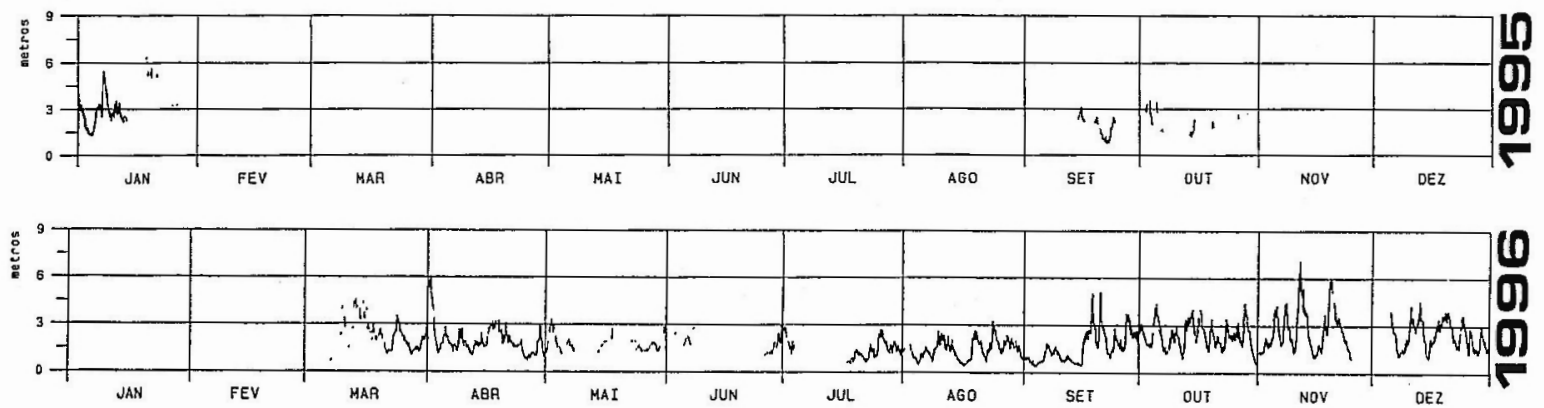

Figura 2 - Altura média da ondulação registada nos ondógrafos da Figueira da Foz (FFOZD - 1995) e Leixões (1995 e 1996). Dados disponibilizados pelo Instituto Hidrográfico.

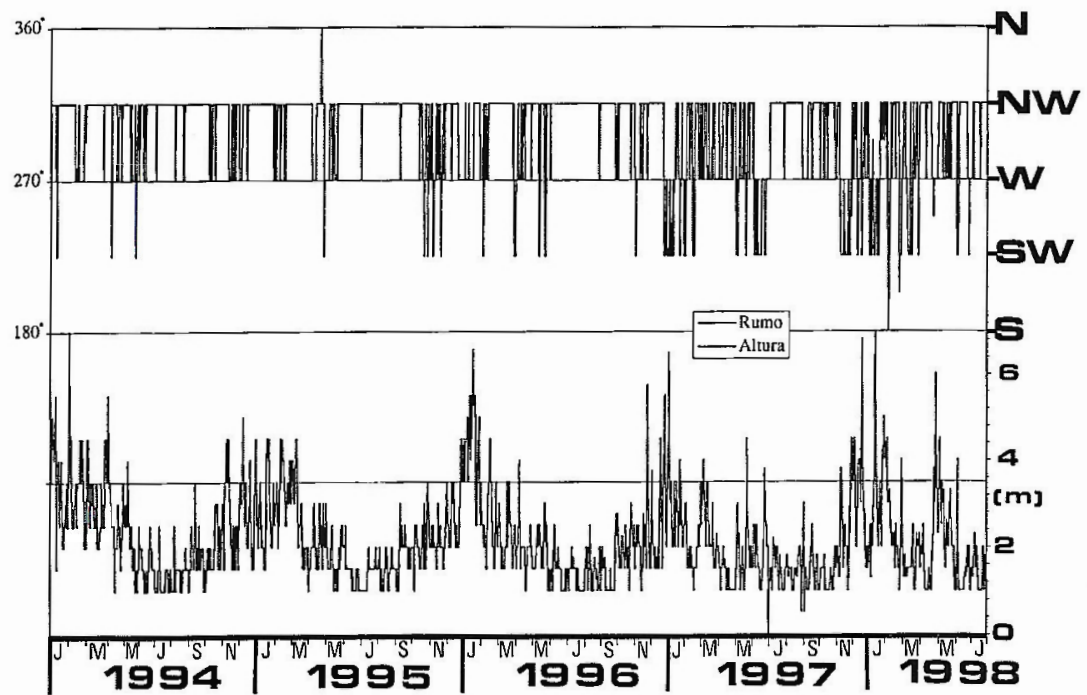

Figura 3 - Altura média e rumo médio diário da ondulação desde 1 de Janeiro de 1994 a 30 de Jurho de 1998. Valores compilados a partir das previsões diárias do Instituto de Meteorologia, apresentadas em jornais diários, relativos à costa ocidental portuguesa a norte do Cabo Carvoeiro. Assinalado o início de cada mês.

\section{Análise e interpretação dos dados}

O Inverno de 1995/96 foi energético; a grande agitação marítima verificada desde meados de Dezembro de 1995 a final de Janeiro de 1996, caracterizada por importante ondulação de $\mathrm{W}$, provocou erosão das praias do sector costeiro analisado. Em períodos de temporal, devido à elevada energia das ondas incidentes e às intensas correntes de retorno geradas, ocorre a remoção, para maior profundidade, de grande quantidade de areia da zona de rebentação e espraiamento. Ao efeito do aumento da agitação somou-se também o que resulta dos rumo de $\mathrm{W}$; nos períodos com ondulação de W não ocorre deslocação de areias, de norte para sul, sobre o estrão do Cabo Mondego, induzindo uma perda acentuada de areia da praia do troço litoral até Buarcos, pois a sua direcção NW-SE só permite deriva para sul (Fig. 4).

Na sequência da perda de areia da praia durante temporais, dá-se geralmente a reposição sob condições de fraca agitação nos períodos de bom tempo subsequente. Contudo, no verão de 1996 tal não se verificou devido a condições meteorológicas anómalas, em que o mau tempo se prolongou, com os restantes 
meses de 1996 a caracterizarem-se por ondulação de pequena altura (geralmente inferior a $2,3 \mathrm{~m}$, a partir de Janeiro) e com um número significativo de dias com ondulação junto à costa de azimute inferior a $\mathrm{N} 283^{\circ}\left(\mathrm{W} 13^{\circ} \mathrm{N}\right)$. Inicialmente - de meados de Outubro de 1995 a Março de 1996 - a perda de areia verificou-se a cotas inferiores à da baixa-mar média, principalmente à custa da barra externa submersa, mas prosseguindo para o interior, de Abril a Junho de 1996, e originando um grande degrau erosivo na praia alta. Em Julho verificou-se uma significativa perda de areia na praia junto ao Teimoso. A partir de meados de Agosto os períodos com ondulação de W ganharam progressiva importância; na segunda quinzena de Dezembro de 1996 ocorreu mesmo uma ondulação exclusiva de $\mathrm{SW}$ e W, muito energética (atingiu 6-7 $\mathrm{m}$ de altura).

A execução mensal de cinco perfis de praia desde Dezembro de 1995 a Abril de 1996 e um em Setembro de 1996 (Almeida \& AMARAl, 1996; Almeida, 1997), permitiu concluir que se verificou um recuo do areal na praia de Buarcos (junto ao Restaurante Costa e também a oeste do Forte) e do Hospital (Gala); no Cabedelo registou-se uma certa manutenção ou mesmo avanço, enquanto que nas praias imediatamente a norte do Cabo Mondego (troço de Quiaios; Fig. 4) não se registou recuo da linha de costa e só ocorreu erosão durante a forte agitação do temporal de Janeiro de 1996. Em nosso entender, este comportamento pode explicar-se fundamentalmente por uma ondulação média mais próxima de $\mathrm{W}$ do que é habitual, realçando-se:

- A sul da embocadura do Mondego (Fig. 4), a orientação SSW-NNE do troço Gala-Cabedelo-molhe sul deve ter originado deriva litoral para norte sob ondulação de $\mathrm{W}$, o que explicaria a retenção de areias de encontro ao molhe sul e acreção na praia do Cabedelo enquanto que a do Hospital (limitada a sul pelo campo de esporões da Gala) sofria de erosão por défice sedimentar.

- A norte da embocadura, a retenção das areias litorais em deriva para sul, de encontro ao Cabo Mondego, originou acreção em Murtinheira-Quiaios e grande erosão em Buarcos.

- Mais a norte, na costa arenosa imediatamente a sul dos molhes do Porto de Aveiro e adjacente campo de esporões, já no trecho em que o défice sedimentar leva a que a capacidade de transporte da ondulação seja saturada por erosão do cordão dunar longilitural, de Fevereiro de 1996 a Abril de 1997 Boto et al. (1997) calcularam um recuo médio de $9,6 \mathrm{~m}$ no sector Vagueira-Praia do Areão (Fig. 4).
Figura 4 - Plano de onduiação, com rumo WNW e período 10s, para a zona da Gala (adaptado de Castanho \& Simóes, 1978) e resultantes sentidos de deriva litoral (assinalados por setas; os troços Quiaios-Cabo Mondego e Gala-Leirosa, sem deriva, estão assinalados por - 0 ), que não permite que as areias de norte ultrapassem o Cabo Mondego. $\mathrm{O}$ troço Cabo Mondego-Buarcos é o único deste sector do litoral em que a deriva se faz sempre para sul, independentemente dos rumos da ondulação. Legenda: SJ - São Jacinto; CN - Praia de Costa Nova; V - Praia de Vagueira; A - Praia de Areão;

MI - Praia de Mira; P - Praia de Palheirão; T - Praia da Tocha; C - Praia de Costinha; Q - Praia de Quiaios; MU - Praia de Murtinheira; CM - Cabo Mondego; B - Praia de Buarcos; F - Praia de Figueira da Foz; CA - Praia do Cabedelo; CG Praia da Cova; CL - Praia de Costa de Lavos; L . Praia da Leirosa; OB - Praia do Osso da Baleia.

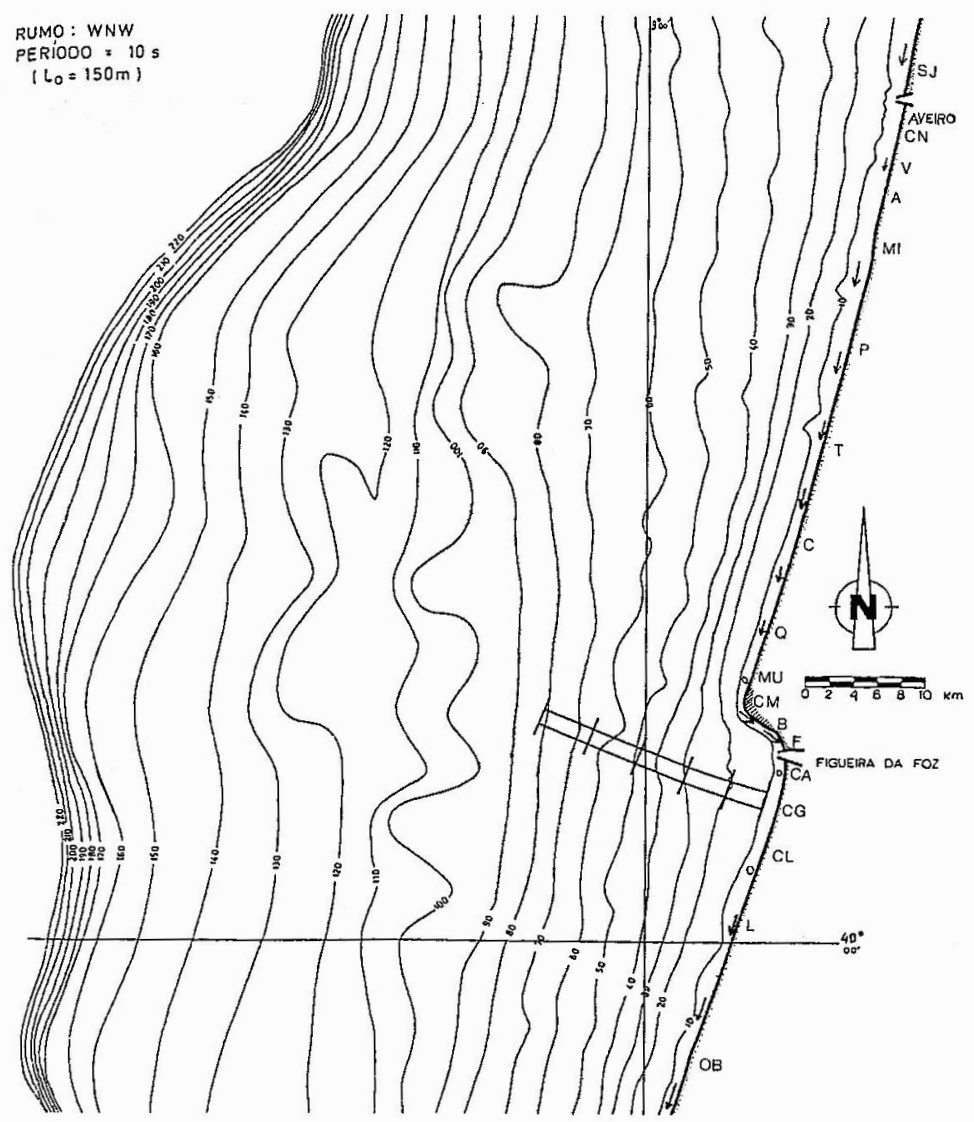


Em 1997 e no $1^{\circ}$ semestre de 1998 , apesar de não ter ocorridoenérgica ondulação de $\mathrm{W}$ como a verificada em Janeiro de 1996, ocorreu uma diminuição da frequência da ondulação de NW e um aumento de SW, o que continuou o quadro de carência da alimentação arenosa das praias a sul do Cabo Mondego.

O reduzido abastecimento sedimentar, inferior à capacidade de transporte litoral, para além de causar a erosão das praias a sotamar, debilita as barras arenosas submersas; isto implica, entre outras consequências, que o efeito de dissipação da energia das ondas incidentes fique muito reduzido. No caso do sector Teimoso-Buarcos, depois de ter sido erodida a barra exterior submersa e o prisma arenoso da praia, a energia da rebentação (embora geralmente fraca) passou a incidir com maior energia directamente no enrocamento, acelerando a sua destruição.

Todavia, a larga escala no tempo e no espaço, a tendência erosiva verificada parece ajustar-se a um modelo de propagação para sul dos problemas erosivos na faixa litoral ocidental portuguesa: logo após as grandes obras de protecção costeira no sector Espinho- Ovar verificaram-se aumentos de erosão no sector Furadouro-Mira (FERREIRA \& DiAS, 1991); mais recentemente, iniciou-se uma ligeira tendência erosiva no sector Mira-Quiaios (BetTencourt \& ÂNGelo, 1992) e que agora também atinge o sector Cabo Mondego-Figueira da Foz (Fig. 4). Este último sector, com orientação NW-SE e situado a sul do grande esporão natural do Cabo Mondego, é mais vulnerável à erosão do que o sector Mira-Quiaios, já que se posiciona a sotamar de um obstáculo à deriva litoral mais persistente e está exposto à agitação de tempestade (de SW e W).

\section{Discussão e conclusões}

Devidoà deriva litoral se fazer fundamentalmente para sul, ao longo da costa (Fig. 4), quer o troço Cabo Mondego-Figueira da Foz, quer o situado imediatamente para norte (Cabo Mondego-Porto de Aveiro) têm sofrido nas últimas décadas evoluções erosivas que resultam, fundamentalmente, da progressiva redução dos acarreios fluviais à costa e da redução do caudal sólido litoral pela extracção de areias a norte de portos e que não são transferidas para sul dos molhes portuários (FERREIRA et al., 1990).

Para além destes condicionantes gerais, de acordo com a monitorização efectuada, a recente erosão do troço Cabo Mondego-Figueira da Foz resultou, fundamentalmente, de uma alteração no quadro meteorológico habitual, num clima de tipo mediterrânico que se caracteriza por apresentar importantes variações inter-anuais. Nesta sucessão de anos particularmente húmidos (final de 1995, 1996, 1997 e 1998) ocorreu uma alteração das características da ondulação, tendose verificado invernos marítimos mais energéticos e verões marítimos atípicos. Apesar de no período analisado não se terem verificado significativas alterações no valor anual da altura da ondulação ao largo, constatou-se uma diminuição na frequência da ondulação de NW e aumento de $\mathrm{SW}$, de que resultaram rumos médios da ondulação mais rodados para W em relação aos anos anteriores.

Nos períodos com ondulação apresentando um azimute junto à costa inferior a $\mathrm{N} 283^{\circ}\left(\mathrm{W} 13^{\circ} \mathrm{N}\right)$, a deriva litoral de areia não transpõe, para sul, o Cabo Mondego; existe acreção no litoral imediatamente a norte, enquanto que se verifica erosão no troço até Buarcos em que, por apresentar uma direcção NW-SE, a deriva litoral se faz sempre para sul. Quando o caudal sólido litoral que atinge um determinado troço da costa não permite a saturação da capacidade de transporte da agitação marítima gera-se um défice sedimentar que tende a ser compensado por erosão das praias na costa a sotamar e a erosão propaga-se nesse sentido. Dado o efeito de promontório representado pelo molhe norte do Porto da Figueira da Foz, a sua cabeça é geralmente o ponto fixo a condicionar a evolução do troço costeiro imediatamente a barlamar da deriva litoral (tendencialmente a norte), função de um dado caudal sedimentar. Caso a alimentação a partir do Cabo Mondego seja muito reduzida, a linha de costa a sotamar tende a rodar para ficar perpendicular ao rumo médio da ondulação que atinge a costa. Assim se explica o início da erosão em 1996, imediatamente a sul do Cabo Mondego, estendendo-se progressivamente para sul até atingir Buarcos e a Praia da Figueira da Foz. Por outro lado, quando os montantes da extracção de areia na praia junto do molhe norte excedem o volume de areia que chega por deriva litoral, a linha de costa recua muito nesse local, passando a ser ela o ponto da costa a condicionar a rotação do troço costeiro a barlamar; neste caso a posição de equilíbrio será, portanto, atingida mais para o interior, acentuando os efeitos erosivos a barlamar.

A recente suspensão da extracção de areia na praia, junto do molhe norte (6 de Março de 1998), contribuiu para a paragem do recuo costeiro e até para uma lenta acreção do areal da Figueira da Foz-Buarcos. Com o retorno às condições meteorológicas habituais, tendo em conta a generalização do défice sedimentar na costa ocidental, é previsível que nos próximos anos se atenue a tendência erosiva, mas é improvável uma significativa reposição do prisma arenoso erodido. Para a recuperação de praias com elevado interesse, nomeadamente turístico, que tenham sofrido erosão devido a condições meteorológicas peculiares, pensamos que se deve recorrer pontualmente à alimentação artificial; após o retorno da ondulação 
habitual, com a cessação do recuo costeiro, a recuperação do troço Teimoso-Buarcos poderia ser ajudada com a deposição na praia de areias grosseiras dragadas do anteporto (por imperativos de navegação).

A situação analisada permite compreender e prever futuras situações de défice sedimentar, neste ou em outros troços da costa portuguesa, quer por uma prolongada variação nas características médias da ondulação, quer pela actual tendência de redução no abastecimento aluvionar ao litoral e pela extracção de areias litorais.

Se não se minimizar a evolução erosiva da costa portuguesa, será de prever o aumento da probabilidade de ocorrência de situações erosivas na proximidade dos promontórios da costa, em particular sob prolongados períodos com uma alteração da ondulação habitual. Passar-se-á de uma muito regular costa baixa e arenosa para uma situação caracterizada por uma costa em arriba e recortada por promontórios naturais e artificiais (esporões e molhes), com estreitas e limitadas praias arenosas.

É urgente minimizar a ocupação da faixa costeira, principalmente evitando as densas frentes urbanas que se continuam a edificar junto ao litoral. Entre o restaurante Costa e o cemitério de Buarcos, iniciou-se em 1998 o loteamento de um empreendimento turístico, numa extensão de cerca de um quilómetro ao longo da marginal, estando prevista a construção de 735 fogos e um hotel, entre outras infra-estruturas. Com a implantação de moradias a estender-se até poucas dezenas de metros da actual linha de costa erosiva, é mais um exemplo do exagero na ocupação antrópica do litoral que se traduz na edificação de densas frentes urbanas e na difícil aplicação dos planos de ordenamento da Orla Costeira, principalmente num troço costeiro já identificado como zona de risco.

Qualquer construção feita na praia ou na sua imediata vizinhança está sujeita a riscos. Exemplifica esta afirmação o sector de Buarcos, no qual a marginal oceânica foi construída no final da década de 80 sobre o próprio prisma arenoso da praia, pois dado o ganho de areia verificado a partir de 1965 , os responsáveis pela intervenção nāo previram que esta viesse a ser erodida. Note-se que a destruição do enrocamento marginal também prova um erro de projecto desta obra, dado que o enrocamento e escadarias de acesso à praia não foram fundados sobre o substrato rochoso. É também necessário que os vários tipos de ocupação e uso an trópico obedeçam a um zonamento de riscos.

Também a opção por obras costeiras que incluam paredões muito reflectivos provoca o progressivo desaparecimento da areia da praia adjacente (OliveirA, 1996). A experiência demonstra ainda que a ocupação do litoral com edificações fixas acaba por induzir a debilitação progressiva deste, com o desaparecimento das áreas sedimentares (praias arenosas, dunas eólicas, estuários, etc.). Não obstante, ainda em 1995 a Câmara Municipal da Figueira da Foz planeou o alargamento da avenida marginal, pretendendo conquistar uma pequena parte do areal da praia da Figueira da Foz.

As reparações das estruturas danificadas pelo mar, geralmente efectuadas com carácter de urgência e executadas tardiamente, ao invés de atempadamente planeadas, revelaram grande precaridade. Os responsáveis por este tipo de intervenções deveriam solicitar a necessária fundamentação científica sobre as causas dos problemas costeiros, bem como considerar a complexidade e variabilidade da dinâmica natural. Para a reparação dos $2 \mathrm{~km}$ de enrocamento da marginal de Buarcos o Estado já gastou 286 mil contos nos últimos dois anos, faltando ainda gastar $400 \mathrm{mil}$; a reparação dos passeios e muros de remate da marginal vai ascender a $150 \mathrm{mil}$ contos. No litoral imediatamente a sul da foz do Mondego, para executar em 1998-99, o Ministério do Ambiente orçamentou em $400 \mathrm{mil}$ contos a reparação dos esporões da Cova-Gala, Lavos e Leirosa.

A monitorização das praias por prolongados períodos reveste-se de grande importância na explicação da sua evolução e na previsão de possíveis tendências. O método de análise privilegiado consiste, essencialmente, na execução periódica de perfis topográficos transversais, conjugada com a análise da ondulação. Neste sentido, para além do acesso a este tipo de dados pela comunidade científica, teria também muito interesse a reactivaçãodo ondógrafo do Cabo Mondego, tanto mais que os poucos existentes podem apresentar longos períodos sem registo, dadas as frequentes avarias, como se verificou durante o ano de 1995 com o ondógrafo de Leixões.

\section{Agradecimentos}

Queremos agradecer a colaboração na monitorização desta faixa de praia, ao Dr. José N. André, Anabela Silva, Pedro Caetano, Adão Mendese diversos alunos da Univ. de Coimbra. Desejamos expressar ainda um reconhecimento especial a outras pessoas e instituições:

- Ao Instituto Hidrográfico, em particular ao Comdt. Seabra de Melo e à Dra. Mariana Costa, a disponibilização da ondulação de 1995 e 1996;

- Ao Prof. Campar de Almeida a disponibilização da descrição paramétrica do estado do mar da Figueira da Foz, adquirida ao Instituto de Meteorologia;

- À Divisão de Ambiente e Recursos Naturais do Centro, em especial ao Eng. Mota Lopes, os esclarecimentos sobre intervenções antrópicas e o acesso a documentação técnica;

- À Junta Autónoma do Porto da Figueira da Foz e à Capitania do Porto da Figueira da Foz, as diversas informações prestadas; 
- Ao Prof. German Flor (Dep. Geologia da Univ. Oviedo), a colaboração na análise da dinâmica sedimentar litoral no âmbito da Acção Integrada Luso-Espanahola ${ }^{\circ}$ E-1/98.

- Ao Sr. Ludgero Guardão, a disponibilização de fotografias da praia da Figueira da Foz relativas ao temporal de 7 de Janeiro de 1996;

- As contribuições a uma primeira versão deste trabalho efectuada pelos Profs. Antunes do Carmo, I. Mota Oliveira, César de Andrade e Fernando Rebelo.

\section{Referências bibliográficas:}

ABECASIS, F.; Matias, M. F.; CARVALHO, J. J. \& VERA-CRUZ, D. (1962) - Methods of determining sand and silt movement along the coast, in estuaries and in maritime rivers. Lab. Nac. Eng. Civil. Technical paper $\mathrm{n}^{\circ} 186$, Lisboa, $25 \mathrm{p}$.

ALMEIDA, A. Campar (1997) - Os efeitos do Inverno de 1995/96 sobre as praias da Figueira da Foz. IV Encontro sobre riscos naturais urbanos (Resumos), I.E.G. - Fac. Letras da Univ. de Coimbra, Coimbra, 24 de Janeiro de 1997, 1 p.

ALMEIDA, A. Campar \& AMARAL, V. (1996) - A acção do Invernode $1995 / 96$ sobre as praias da Figueira da Foz.Cadernos de Geografia, $\mathrm{n}^{\mathbf{0}} 15$, Coimbra, pp. 55-60.

ALMEIDA, J. Lopes de (1991) - Aplicação de modelos numéricos ao estudo da onda ce "mareta" no Porto da Figueira da Foz. Estudos de Engenharia Civil, Coimbra, 3, 1/2, pp. 99-111.

ALMEIDA, J. Lopes de \& SANTOS, F. Seabra (1991) - A onda de maré; geração, propagação, caracterização, modelação. O caso do estuário do Mondego. Provas de Aptidão Pedagógica e Capacidade Científica, Texto policopiado, Universidade de Coimbra.

ANDRADE, C.; TEIXEIRA, S.; REIS, R. \& FREITAS, C. (1996) The record of storminess of the Portuguese NW coast in newspaper sources. In: Partnership in Coastal Zone Management. J. Taussik \& J. Mitchell (eds.). Samara Publishing Limited, Cardigan, pp. 159-166.

BETTENCOURT, P.\& ÂNGELO, C. (1992) - Faixa costeira Centro Oeste (Espinho - Nazaré): enquadramento geomorfológico e evolução recente. Geonovas, ñ especial 1 (A Geologia e o Ambiente), Lisboa, pp. 7-30.

BOTO, A.; BERNARDES, C. A. \& DIAS, J. Alveirinho (1997) Erosão litoral e recuo da linha de costa entre a Costa Nova e a Praia do Areão, Portugal. Volume especial "Colectânea de ideias sobre a zona costeira de Portugal", Assoc. Eurocoast-Portugal (Ed.), pp. 449-467.

CARVALHO, J. (1971) - Características das ondas na rebentação (caso de batimetria paralela). Sua aplicação ao transporte

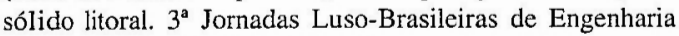
Civil, LNEC, p. III-2-1 a III-2-15.

CARVALHO, J. Reis de \& BARCELÓ, J. (1966) - Agitação marítima na costa Oeste de Portugal Metropolitano - Contribuição para o seu estudo. Lab. Nac. Eng. Civil., Memória n² 290, Lisboa, $34 \mathrm{p}$.
CARVALHO, M. (1992) - Valores extremos de agitação maritima (Figueira da Foz). Tratamento local dos dados existentes. Rel. 13/92-A, PO-WAVES, IH-LNEC, 108 p.

CASTANHO, J. Pires; GOMES, N. A.; OLIVEIRA, I. B. Mota \& SIMÕES, J. Pinto (1981) - Coastal erosion caused by harbour works on the Portuguese coast and corrective measures. 24 th Naveg. Cong., Edinburg, pp. 877-898.

CASTANHO, J., Gomes, N., CARVALHO, J., VERA-CRUZ, D., ARAÚJO, O. Teixeira, A. \& WEINHOLTZ, M. (1974) Means of controlling littoral drift to protect beaches, dunes, estuaries and harbour entrances. Estabishment of artificial beaches. Mem. $L N E C, 448$, Lisboa, $26 \mathrm{p}$.

CASTANHO, J. Pires \& SIMÕES, J. Pinto (1978) - Estudo da erosão litoral a Sul da embocadura do Rio Mondego, (policopiado), Lisboa, LNEC, $69 \mathrm{p}$.

CONSULMAR (1973) - Porto da Figueira da Foz. Plano geral das obras interiores do porto da Figueira da Foz e de valorização do estuário do Mondego. Esquema geral do Plano e plano parcial das obras da $1^{a}$ fase. (Junho 1973), Rel. policopiado, $105 \mathrm{p}$.

CUNHA, P. Proença (1997) - Evolução recente e riscos geológicos costeiros da áreaestuarina do Rio Mondegoe regiãoenvolvente. IVEncontro sobre riscosnaturais urbanos (Resumos), Instituto de Estudos Geográficos - Fac. Letras da Univ. de Coimbra, Coimbra, 24 de Janeiro de 1997, pp. 1-4.

CUNHA, P. Proença (1998a) - Impactes antrópicos na área dunar da Figueira da Foz - Leirosa. Seminário Dunas da Zona Costeira de Portugal (Actas), Associação Eurocoast-Portugal (Ed.), 4-6 de Junho de 1998 - Leiria, pp. 105-118.

CUNHA, P. Proença (1998b) - Impactes antrópicos nos sistemas sedimentares da área da Figueira da Foz - contribuição para a análise das transformações globais e do desenvolvimento sustentável das zonas costeiras. $1^{\circ}$ Congresso da Bacia do Mondego (Resumos), Universidade Internacional da Figueira da Foz, pp. 1-2.

CUNHA, P. Proença; DINIS, J. L. \& ANDRÉ, J. Nunes (1998) Interacção entre as operações de dragagem no Porto da Figueira da Foz e a dinâmica sedimentar no Estuário do Mondego e costa adjacente (Portugal central), Seminário sobre Dragagens, dragadose ambientes costeiros (Actas), Associação EurocoastPortugal (Ed.), Lisboa, pp. 27-45.

CUNHA, P. Proença; DINIS, J. L. \& REIS, R. Pena dos (1997b) Relatório final do projecto de investigação PEAM/C/GEN/ 247/93 (Prog. Esp. Ambiente - JNICT/DGA): "Avaliação das modificações antrópicas actuais nos sub-ambientes sedimentares do Estuário do Mondego". Faculdade de Ciências e Tecnologia da Univ. de Coimbra, (policopiado), 152 p. e anexos (151 p. e uma carta de sedimentos do estuário).

CUNHA, P. Proença; DINIS, J. L.; SILVA, A. Freire da \& ANDRÉ, J. N. (1995b) - Evolução estuarina condicionada por intervenções portuárias: modificações recentes no sector intermédio e distal do Estuário do Mondego. Memórias e Notícias, Publ. Mus. Lab. Min. Geol. Univ. Coimbra, n 120, pp. 95$-117$. 
CUNHA, P. Proença; PINTO, J. \& DINIS, J. L. (1995a) - Unidades fisiográficas e modificações recentes no Estuário do Mondego, por análise de coberturas de fotografia aérea. Pub. Museu $e$ Laboratório Mineralógico e Geológico da Univ. Porto, Memória nº 4, pp. 405-409.

CUNHA, P. Proença; PINTO, J. \& DINIS, J. L. (1997a) - Evolução da fisiografia e ocupação antrópica na área estuarina do Rio Mondego e região envolvente (Portugal centro-oeste), desde 1947. Territorium, Revista de Geografia Física aplicada no ordenamento do território e gestão de riscos naturais, Coimbra, 4, pp. 99-124.

CUNHA, P. Proença; SILVA, A. Freire da; ANDRÉ, J. Nunes \& CABRAL, M. Cristina (1997d) - Considerações sobre a evolução actual do litoral entre a Figueira da Foz e Nazaré. Volume especial "Colectânea de ideias sobre a zona costeira de Portugal", Assoc. Eurocoast-Portugal (Ed.), pp. 503-524.

DIAS, J. Alveirinho; FERREIRA, O. \& PEREIRA, A. R. (1994) Estudo sintético de diagnóstico da geomorfologiae da dinâmica sedimentar dos troços costeiros entre Espinho e Nazaré Relatorio final. ESAMIN, (policopiado), 303 p.

DINIS, J. L. \& CUNHA, P. Proença (1998) - Impactes antrópicos no sistema sedimentar do Estuário do Mondego. Sociedade e Território, Editora Afrontamento, Porto, 27, pp. 47-59.

DUARTE, D. N. \& REIS, R. Pena dos (1992) - Estudo preliminar da evolução da linha de costa adjacente à embocadura do estuário do Mondego entre 1801 e 1989. Estimação de taxas de acreção e erosão costeiras. Actas III Congreso Geologico de Españay VIII Congreso Latino-Americano de Geologia. Salamanca, tomo 2, pp. 146-150.

FERREIRA, O. (1993) - Caracterização dos principais factores condicionantes do balanço sedimentar e da evolução da linha de costa entre Aveiro e o Cabo Mondego. Dissertação de Mestrado na Univ, de Lisboa, (policopiado), $168 \mathrm{p}$.

FERREIRA, O. \& DIAS, J. Alveirinho (1991) - Evolução recente de alguns troços do litoral entre Espinho e o Cabo Mondego (Portugal). Actas $2^{\circ}$ Simp. sobre protecção e revalorização da faixa costeira do Minho ao Liz. Porto, pp. 85-95.

FERREIRA, O. \& DIAS, J. Alveirinho (1997) - Avaliação da acção de temporais na costa oeste portuguesa. Volume especial "Colectânea de ideias sobre a zona costeira de Portugal", Assoc. Eurocoast-Portugal (Ed.), pp. 429-447.

FERREIRA, O.; DIAS, J. Alveirinho \& TABORDA, R. (1990) Sea-level rise, sediment input and shoreline retreat: the case of Aveiro - Cabo Mondego (Portugal). Littoral 1990 (Symp. Intern. Assoc. EUROCOAST), Marselha, pp. 314-318.

GIBERT, A. C. (1958) - Vantagens do uso da prata radioactiva no estudo do transporte sólido no Mar. Comun. na $1^{\circ}$ Reunião dos técnicos portugueses de energia nuclear, Lisboa, Janeiro 1958, (policopiado), $12 \mathrm{p}$.

GILBERT, A.; FERREIRA, M. G.; CORDEIRO, S.; ABECASIS, F. M. \& CARVALHO, J. R. (1960) - Tracing undersea sand movement with radiactive silver. Lab. Nac. Eng. Civil Technical paper $\mathrm{n}^{\circ} 150$, Lisboa, $5 \mathrm{p}$.
IMPACTE (1993) - Estudo de impacte ambiental do terminal de granéis sólidos do Porto da Figueira da Foz. (IMPACTE, Lda. - Novembro 1993), $126 \mathrm{p}$.

L.N.E.C. (1961) - Ensaios laboratoriais do Porto da Figueira da Foz - Estudo dos movimentos aluvionares na costa com o emprego de areias radioactivas. $3^{\circ}$ Relatório do Lab. Nac. Eng. Civil, policopiado, Lisboa.

L.N.E.C. (1970) - Estudo em modelo reduzido do Porto da Figueira da Foz. $5^{\circ}$ Relatório do Lab. Nac. Eng. Civil, policopiado, Lisboa.

NOIVO, L. S. (1994) - Human activities in conflict in the coastal zone: study case of Figueira da Foz. Gaia, 9, pp. 115-118.

OLIVEIRA, I. Mota; VALE, A. \& MIRANDA, F. (1982) - Littoral problems in the Portuguese west coast. Coastal Engineering Proceedings, vol. III, pp. 1950-1969.

OLIVEIRA, I. Mota (1996) - Proteger ou não proteger, ou sobre a viabilidade de diferentes opções face à erosão da costa oeste portuguesa.Actas do III Congresso Nacional da Água, Lisboa, pp. 1-24.

PIRES, H. \& PESSANHA, L. (1986a) - Wave power climate of Portugal. Hydrodynamics of ocean wave-energy utilization. Proceedings of IUTAM Symposium, Lisboa, pp. 157-167.

PIRES, H. \& PESSANHA, L. (1986b) - Estima da distribuição da probabilidade dos valores extremos utilizando séries climatológicas curtas. Revista do Inst. Nac. MG, 24 p.

PITA, C. \& SANTOS, J. (1989) - Análise dos temporais da costa oeste de Portugal Continental. Rel. 1/89-A, PO-WAVES, IH-LNEC, $29 \mathrm{p}$.

REBELO, F. (1978) - Os temporaios de 25/26 de Fevereiro de 1978 no Centro de Portugal. Finisterra, 13 (26), pp. 244-253.

SANTOS, F. Seabra; ALMEIDA, J. \& CARMO, J. Antunes (1991) - Estudo da agitação marítima. 153 p. In Relatório final do projectode investigação - "Lançamento de bases para o estudo integrado do estuário do Mondego". Faculdade de Ciências e Tecnologia da Univ, de Coimbra, (policopiado).

VICENTE, C. (1990) - Evolução costeira devida a obras portuárias: casos da praia da Figueira da Foz e da embocadura da Ria de Aveiro. $1^{\circ}$ Simpósio sobre a proteç̧ão e revalorização da faixa costeira do Minho ao Liz (Comunicaçôes), Porto, pp. 164-177.

VICENTE, C. \& PEREIRA, M. (1986) - Análise da evolução da praia da Figueira da Foz. Lab. Nac. Eng. Civil. Rel. 106/86NET, Lisboa, $51 \mathrm{p}$. 
territorium 5.1998

ESTAMPA $]$

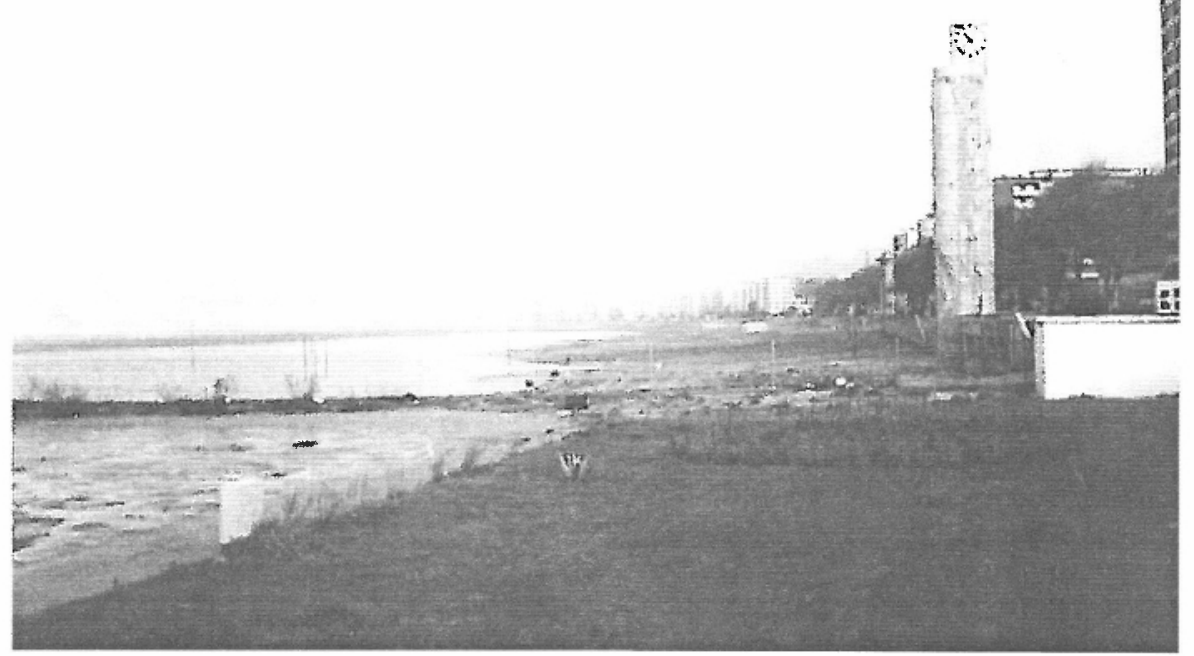

Foto 1 - Panorâmica da praia da Figueira da Foz, na manhã do dia 7 de Janeiro de 1996, já depois de um grande decréscimo na agitação marítima do temporal no mar que atingiu $9,3 \mathrm{~m}$ de altura. Observa-se a inundação da praia que quase atingiu a base da torre do relógio.

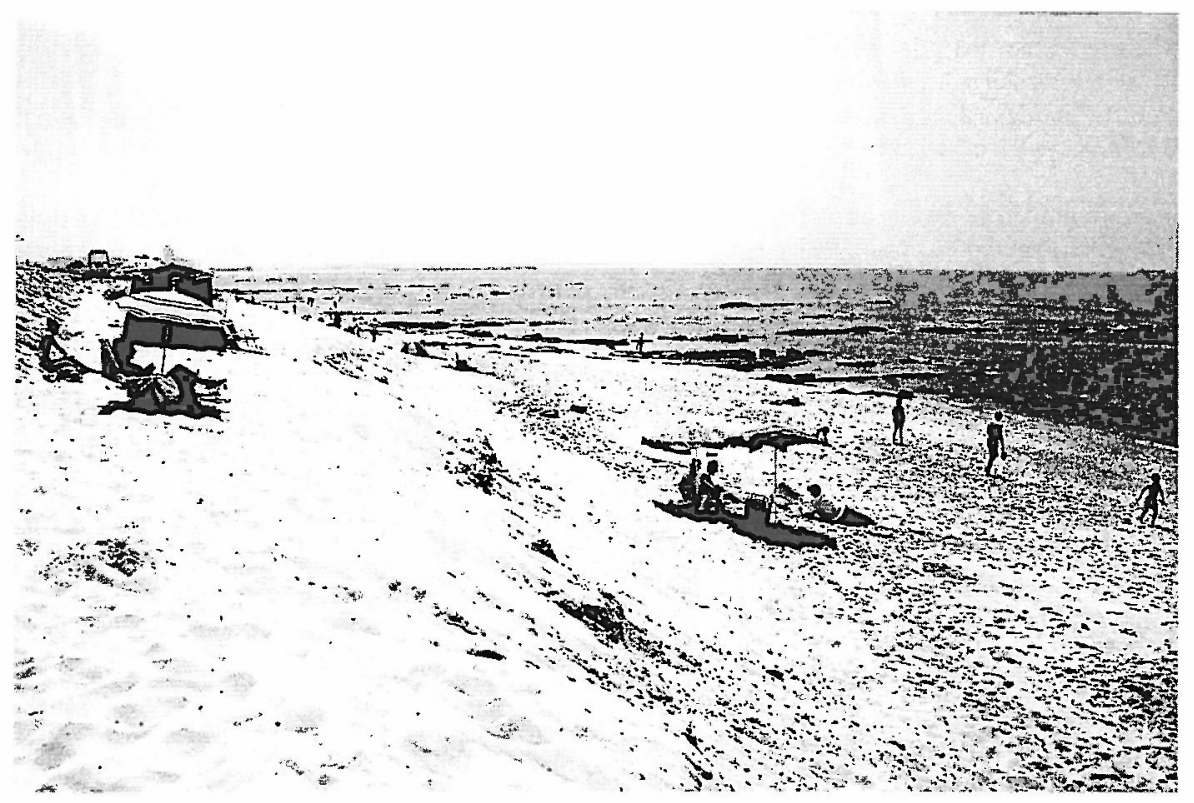

Foto 2 - Aspecto do areal entre o Forte de Buarcos e o Teimoso em 17/07/1996. Note-se o grande degrau erosivo talhando a praia alta. $\mathrm{O}$ adjacente enrocamento da avenida marginal foi posteriormente destruído na totalidade. A fotografia foi tirada para sul, a partir do restaurante Costa. 


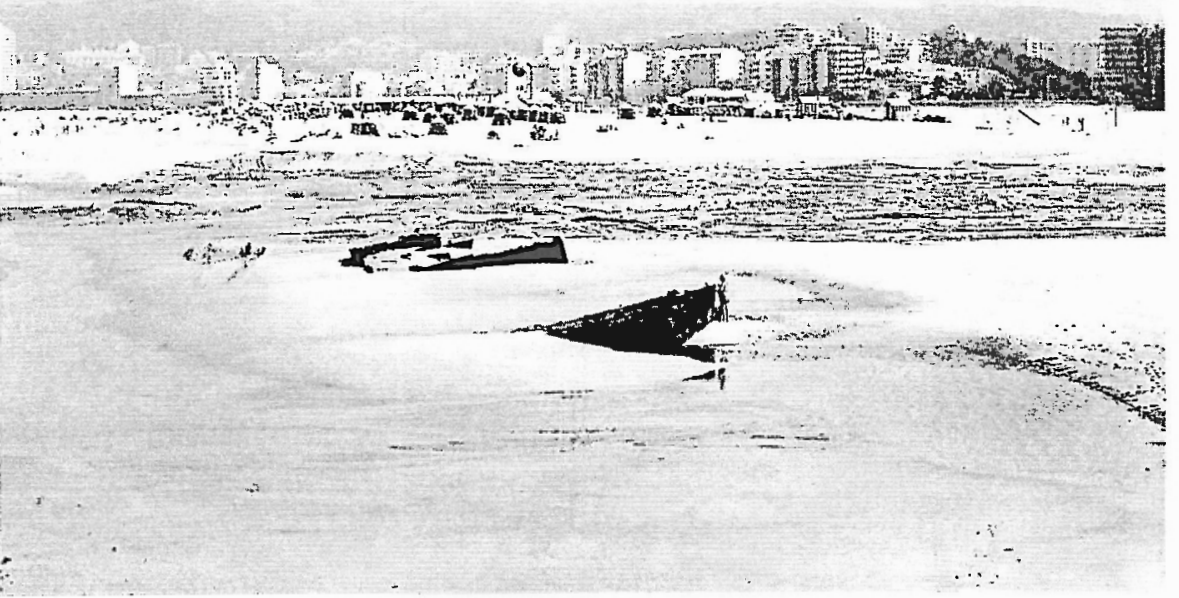

Foto 3 - A extracção de areia na praia da Figueira da Foz (junto do molhe norte) gerou uma enorme depressão, com rebaixamento em cerca de $8 \mathrm{~m}$, expondo um barco soterrado durante 32 anos. Note-se a descida topográfica dos chapéus de praia junto da Bola Nivea e a berma erosiva que se estende para norte $(17 / 07 / 1996)$.

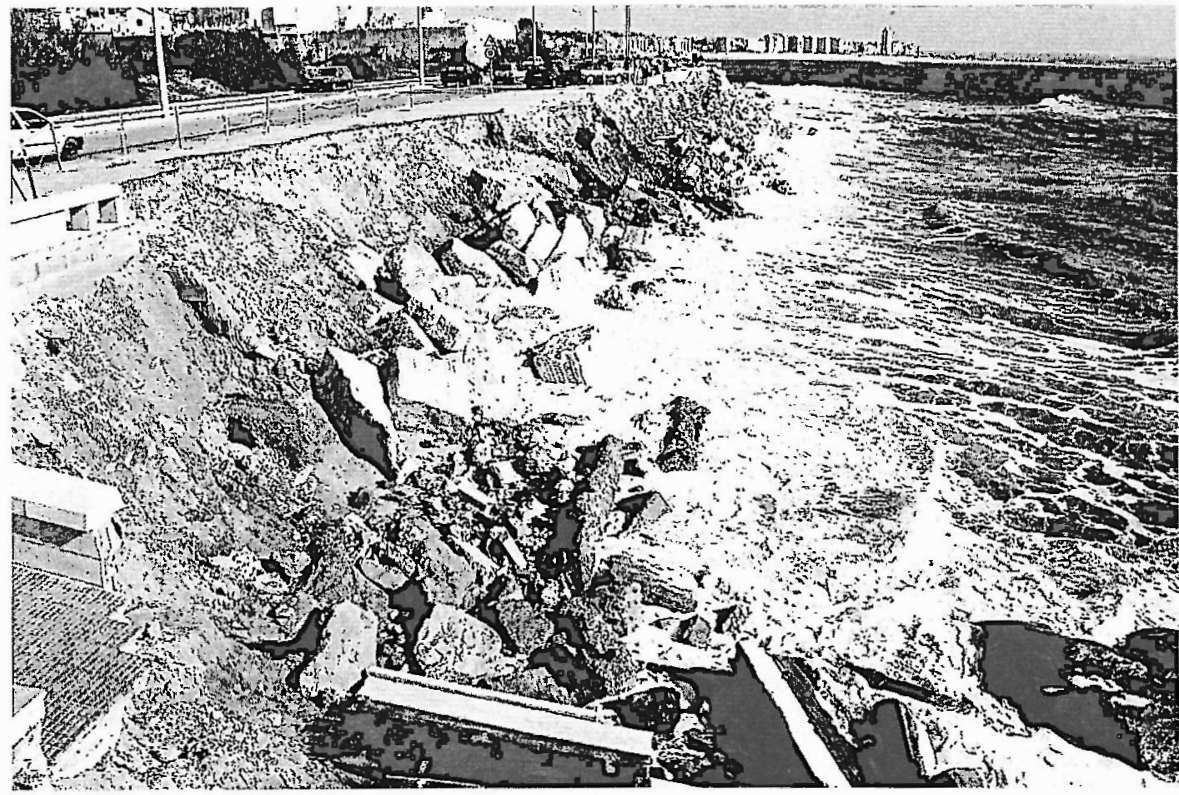

Foto 4 - Aspecto da destruição do enrocamento da Marginal Oceânica, junto do cemitério de Buarcos (troço Teimoso-Buarcos), durante uma preia-mar de maré viva (altura de $3,8 \mathrm{~m} \mathrm{Z}$.H.) e com fraca ondulação (1,5 m de altura) de WNW (9/03/1997). São visíveis os blocos de calcário branco depositados recentemente, mas que não impediram o desmoronamento progressivo da própria estrada marginal.

Note-se a completa erosão do prisma arenoso da praia, que atingia $2,5 \mathrm{~m}$ de espessura na antiga frente do enrocamento, aflorando o substrato rochoso do Jurássico Superior. Em primeiro plano estão os destroços de uma escadaria de acesso à praia. 
ESTAMPA III

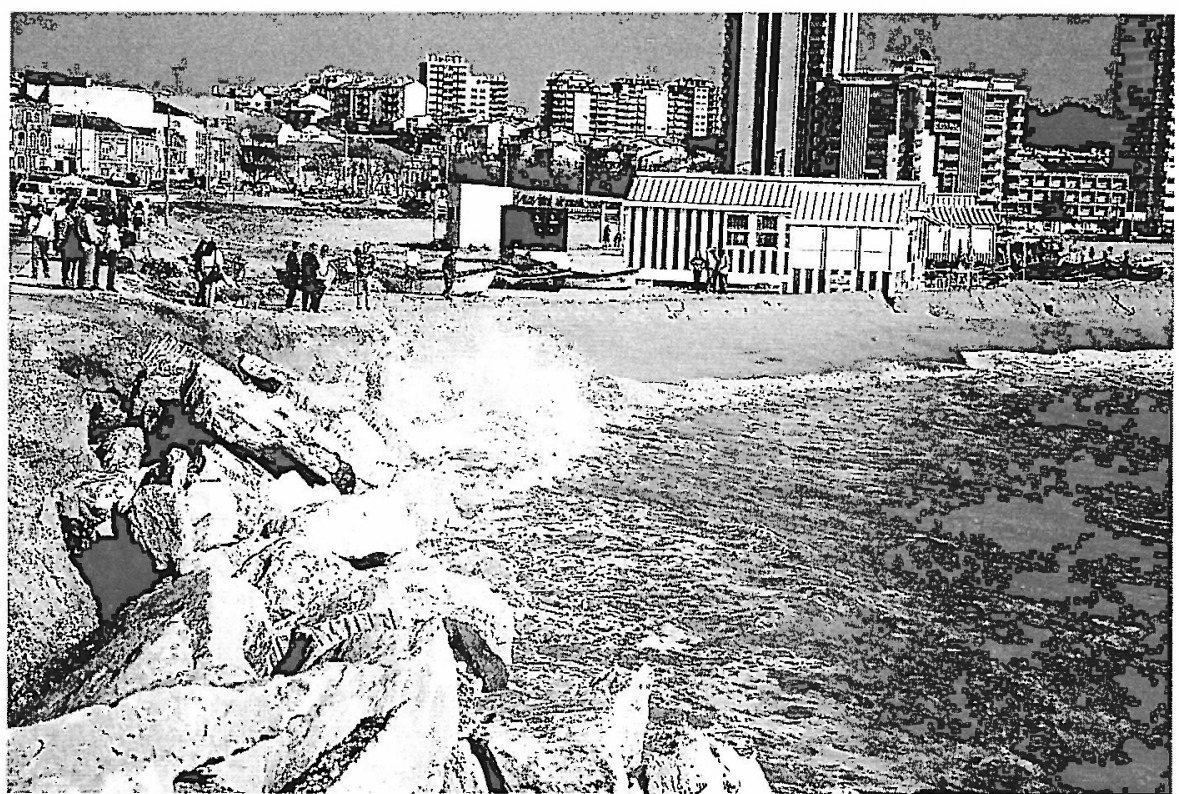

Foto 5 - Erosão da praia na curva da estrada marginal, junto ao Forte de Buarcos, durante uma preia-mar de maré viva (altura de 3,8 $\mathrm{m}$ Z.H.) e com fraca ondulação (1,5 m de altura) de WNW (9/03/1997). É visível o aspecto turvo da água na zona de rebentação, evidenciando o transporte litoral de sedimentos para sul, bem como o degrau erosivo (que atingiu $1,3 \mathrm{~m}$ de altura) a impedir o acesso dos botes de pesca à praia alta e que se prolonga para sul. Repare-se nos enormes blocos de calcário branco depositados em

intervenção de urgência e que não impedem a erosão da Marginal e da praia, levando à posterior desmontagem dos "apoios de praia" ainda visíveis nesta fotografia.

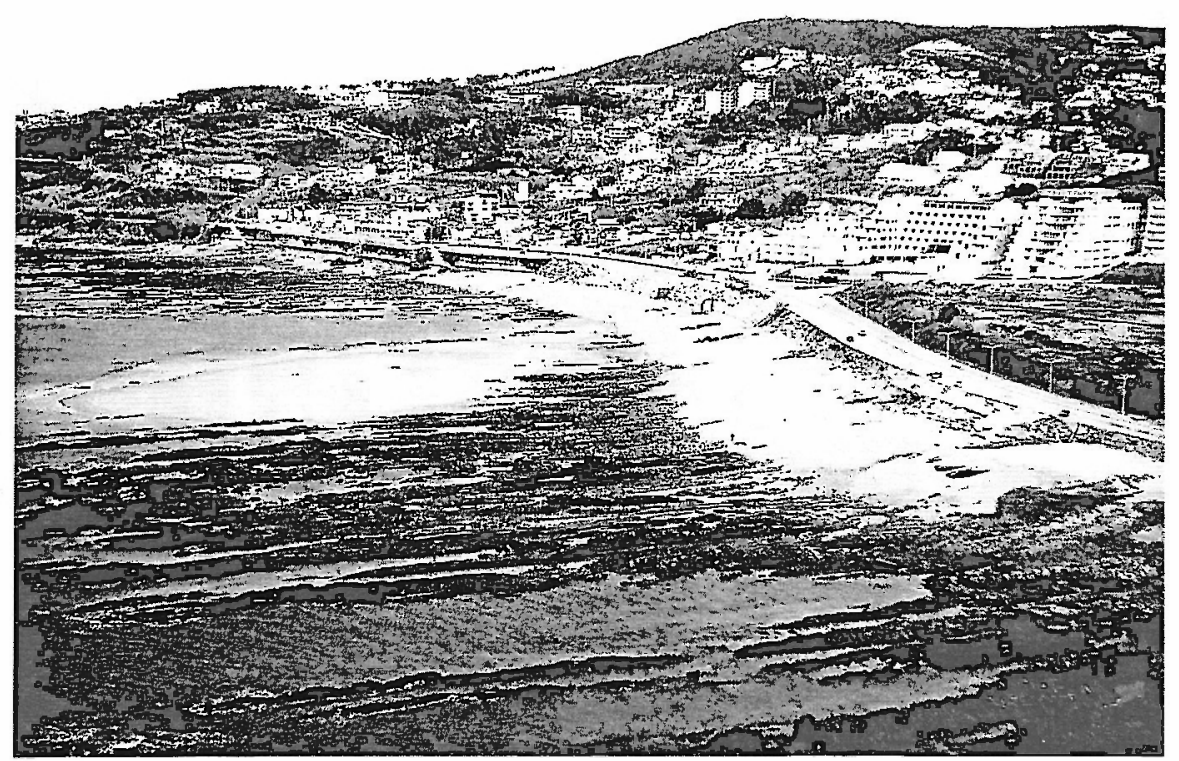

Foto 6 - Panorâmica aérea do troço litoral entre o Cabo Mondego e o cemitério de Buarcos, na baixa-mar de maré viva, evidenciando a grande exposição do substrato rochoso e os trabalhos de reparação do enrocamento da avenida marginal. Note-se que grande parte da escassa cobertura de areia que é visível se acumulou durante um curto período ( $1^{\mathrm{a}}$ semana de Janeiro de 1998) com forte ondulação de NW (atingiu cerca de $5 \mathrm{~m}$ de altura, ao largo). No lado direito da fotografia observa-se a extremidade NW da área onde se executam trabalhos de loteamento para a construção de uma densa frente edificada junto da marginal. 